\title{
Pharmacogenetic implications in the management of metabolic diseases in Brazilian populations
}

\author{
Rosario Dominguez Crespo Hirata ${ }^{1}$, Alvaro Cerda ${ }^{2}$, Fabiana Dalla Vechia Genvigir ${ }^{1}$, Mario \\ Hiroyuki Hirata $^{1^{*}}$
}

\begin{abstract}
${ }^{1}$ Department of Clinical and Toxicological Analyses, School of Pharmaceutical Sciences, University of Sao Paulo, Sao Paulo, SP, Brazil, ${ }^{2}$ Center of Excellence in Translational Medicine, CEMT-BIOREN, Departamento de Ciencias Básicas, Universidad de La Frontera, Temuco, Chile
\end{abstract}

\begin{abstract}
Dyslipidemia, diabetes, obesity and hypertension are common metabolic diseases. In the last decades, unhealthy lifestyle and aging have leads to an increased incidence of these diseases, increasing morbidity and mortality by cardiovascular causes. The treatment of metabolic diseases includes lifestyle interventions as healthy diet and physical exercise, as well as pharmacological interventions. Several drugs are available for the management of metabolic diseases including among others lipidlowering antidiabetics and antihypertensive drugs. Variability in response to these drugs is influenced by both genetic and non-genetic factors. Polymorphisms in genes related to drug pharmacokinetics and pharmacodynamics have been shown to influence drug efficacy and safety. This review is focused on pharmacogenetic studies related to the management of metabolic diseases in samples of the Brazilian population. Associations of variants in drug metabolizing enzymes and transporters, drug target and metabolism-related genes with the efficacy and safety of lipid-lowering, antidiabetic and antihypertensive drugs are described. Most pharmacogenetic studies in Brazil have focused in pharmacological response to a small group of drugs, as statins and some antihypertensives, while there are almost no studies on antidiabetic and antiobesity drugs. Some studies reported significant associations of gene polymorphisms with drug response confirming previous data from other populations, whereas other works did not replicate, which may relay on the genetic admixture of our population. In conclusion, further studies are necessary considering larger sample sizes, new unexplored drugs and more genetic variants to obtain stronger conclusions to explore clinical applications of pharmacogenetic studies in our population.
\end{abstract}

Keywords: Pharmacogenetics. Metabolic diseases. Gene polymorphism. Drug response.

\section{INTRODUCTION}

Metabolic diseases are interrelated disorders that contribute to the development of cardiovascular disease, which have experienced a notable increase in their rates in the last decades due to several contributing factors as ageing and mainly those related to life-style changes (unhealthy dietary pattern, physical inactivity and sedentary lifestyle, smoking, among others) which are reflected in high prevalence of obesity, type 2 diabetes (T2D) and, lately, metabolic syndrome (MetS) worldwide;

\footnotetext{
*Correspondence: R. D. C. Hirata. Departmento de Análises Clínicas e Toxicológicas, Faculdade de Ciências Farmacêuticas, Universidade de São Paulo. Av. Prof. Lineu Prestes, 580 B-17 - 05508-900 São Paulo, SP, Brazil. Tel.: +55-11-30913660. E-mail: rosariohirata@usp.br
}

including Brazil with a prevalence of MetS of almost $30 \%$ (De Carvalho Vidigal et al., 2013).

The origin of metabolic disorders can be explained by a number of conditions that lead to a proinflammatory status, such as over nutrition/obesity, insulin resistance, dyslipidemia and hypertension. Among them, obesity is a well-known risk factor conducting to atherosclerosis by increasing glucose levels, blood pressure and impairing lipid profile. Moreover, the increase of inflammatory mediators related to the expansion of adipose tissue and the changes observed in adipose tissue in response to over nutrition/obesity induce insulin resistance and oxidative stress, with the potential to impair several biological pathways that contributes to the establishment of insulin resistance and further development of atherosclerosis and cardiovascular diseases (Yoo, Choi, 2014). 
Changes in life-style are the first line treatment for the management of metabolic diseases. Dietary changes and physical activity improve metabolic parameters, mainly by changing anthropometric measures related to body composition as the reduction of fat mass related to visceral obesity. Nevertheless, when dietary changes are not enough to maintain patients with metabolic diseases at a low cardiometabolic risk, pharmacological intervention is necessary.

The pharmacological management of metabolic diseases has become a challenge due to the multifactorial components of these diseases, in which many times insulin resistance/T2D, hypertension and dyslipidemia coexist. Moreover, aging of the population and the increasing young age at which these alterations occurs result in long term exposure to the therapeutical drugs (GouniBerthold, Berthold, 2014). Moreover, it is well known that drug response, as effectiveness, safety and adverse drug reactions, depends on genetic and non-genetic factors, such as environmental/nutritional factors, drug interactions and drug metabolism, that could determinate the individual response to the therapeutical drugs.

Several pharmacogenetic studies have been performed in different populations around the world, in order to elucidate the influence of gene polymorphisms on the response to drugs used in the management of hyperglycemia, high blood pressure (BP), dyslipidemia and other metabolic diseases. In this way, Brazilian populations have been proposed as an interesting subject to be evaluated due to the difficulty to use an extrapolation of pharmacogenetic studies from other populations. The extensive miscegenation resulted in a genetic admixture from three major ethnical components, Europeans, Africans and Amerindians. The complex ancestral component of our population has important implications for pharmacogenetic studies and their applications (Cerda, Hirata, Hirata, 2014).

This review is focused on the pharmacogenetic studies that investigate the influence of gene polymorphisms on response to drugs used for treatment of metabolic diseases in Brazilian populations.

\section{PHARMACOGENETICS AND DYSLIPIDEMIA}

\section{Dyslipidemia}

Dyslipidemia is an important risk factor for coronary artery disease (CAD) and stroke. Several long-term prospective studies have consistently shown that characteristic alterations in lipid profile observed in dyslipidemia, such as hypercholesterolemia and hypertriglyceridemia (isolated or mixed if both are present), as well as low levels of high-density lipoprotein (HDL) cholesterol, have increased incidence of cardiovascular disease (CVD). These alterations in the lipid profile are etiologically classified as primary dyslipidemia, when the cause is of genetic origin; or secondary, if the alteration in the lipid profile is a consequence of inadequate life-style, some morbid conditions or as an adverse reaction to drugs (Faludi et al., 2017).

Prevention and a proper and timely management of dyslipidemia can markedly reduce morbidity and mortality due to cardiovascular causes. The treatment of dyslipidemia includes non-pharmacological strategies as a first line intervention, being recommended to modify lifestyle through nutritional therapy, weight-loss, reduction of alcohol intake, physical activity, among others. In high cardiovascular risk patients, as well as those patients with moderate risk who do not reach the therapeutic goals with lifestyle modifications, pharmacological intervention should be prescribed (Faludi et al., 2017).

Several drugs are available for the treatment of dyslipidemia and the choice of a specific medicine will depend on the type of dyslipidemia according to the altered parameter in lipid profile. Regarding cholesterollowering, statins are the most common drugs, with an important body of evidence supporting their benefits in preventing CVD in hypercholesterolemic patients. Also the ezetimibe (an inhibitor of cholesterol absorption) and resins (bile acid sequestrants) could be used in patients with statin intolerance or even could be used in association in patients at a high cardiovascular risk. Regarding treatment of hypertriglyceridemia, fibrates are the first choice, but also niacin and omega-3 fatty acids are available pharmacological strategies (Gryn, Hegele, 2014; Faludi et al., 2017).

\section{Cholesterol-lowering drugs}

Statins are the main focus of the pharmacogenomic studies on lipid-lowering therapy probably because they are very effective to treat hypercholesterolemia and to reduce the cardiovascular risk of patients with metabolic diseases. Statins also have pleiotropic effects that help improve endothelial function, stabilize plaques, and decrease inflammation contributing for primary and secondary prevention of cardiovascular and cerebrovascular diseases. Non-statin drugs, used as monoor combined therapy, are becoming also focus of recent pharmacogenetic studies, mainly for patients with severe hypercholesterolemia, and/or who experienced lack of response or statin-induced muscular events (Gryn, Hegele, 2014; Alfonsi, Hegele, Gryn, 2016). 
Statins are cholesterol synthesis inhibitors that competitively block 3-hydroxy-3-methylglutarylcoenzyme A reductase (HMGCR), the enzyme limiting the de novo synthesis of cholesterol in the liver. Statins are effective, well-tolerated and safe lipid-lowering drugs, but some patients do not respond to treatment and others experience adverse events, such as myopathy. The variability in the response to statins is attributed to genetic and non-genetic factors, such as lifestyle, drug interactions, intolerance or lack of adherence to pharmacotherapy (Gryn, Hegele, 2014; Patel et al., 2014; Alfonsi, Hegele, Gryn, 2016).

Pharmacogenetic studies of statins have focused mainly on genes in pharmacokinetic and pharmacodynamic pathways, as well as genes involved in lipid metabolism. Polymorphisms in these genes have been associated mainly with variability in statins efficacy and safety and with risk for cardiovascular events (Patel et al., 2014; Alfonsi, Hegele, Gryn, 2016; Leusink et al., 2016; Ruaño et al., 2016).

\section{Pharmacokinetics-related genes}

Several studies have reported that polymorphisms in genes encoding drug metabolizing enzymes influence the liver metabolism of specific statins and can cause a relevant effect on therapeutic response and the risk of adverse effects (Gelissen, McLachlan, 2014). Results from studies in Brazilian sample populations that investigated the influence of pharmacokinetics-related genes on response to statins are summarized in Table I.

\section{Drug metabolizing enzymes and transporters}

Cytochrome p450 (CYP) enzymes, such as CYP3A4 and CYP3A5, are involved in the metabolism of several classes of drugs including statins. Polymorphisms in $C Y P 3 A 4$ and $C Y P 3 A 5$ genes have been shown to influence the response to statins, including resistance to pharmacotherapy in other populations (Gelissen, McLachlan, 2014; Alfonsi, Hegele, Gryn, 2016).

Two studies investigated CYP $3 A 4$ polymorphisms in Brazilian subjects with hypercholesterolemia. CYP3A4*1B (g.-392A $>$ G), CYP $3 A 4 * 22($ g. $15389 \mathrm{C}>\mathrm{T})$ alleles were not associated with cholesterol-lowering response and risk for adverse drug reactions (ADR) after long term treatment with simvastatin (Fiegenbaum et al., 2005a). Similarly, our group reported that $C Y P 3 A 4 * 1 B$ did not influenced the serum lipids reduction after short term treatment with atorvastatin (Wilrrich et al., 2013).

CYP3A5 polymorphisms were also evaluated in Brazilian samples. The $C Y P 3 A 5 * 3 C$ and $* 1 D$ alleles did not influence the response to simvastatin (Fiegenbaum et al., 2005a) and atorvastatin (Willrich et al., 2013). Interestingly, our group observed that carriers of the haplotype $C Y P 3 A 5 * 3 A$, a combination of $* 3 \mathrm{C}$ and $* 1 \mathrm{D}$ alleles, showed reduced efficacy of atorvastatin compared to non-carriers (Willrich et al., 2008). Moreover, the CYP3A5 AGT haplotype, which includes the *3C allele, was associated with lower basal $C Y P 3 A 5 \mathrm{mRNA}$ expression in peripheral blood mononuclear cells (Willrich et al., 2013).

Adenosine triphosphate (ATP)-binding cassette $(\mathrm{ABC})$ transporters are a family of efflux transporters that are involved in the bioavailability of several drugs and some statins. The most commonly studied is the ABCB1, also known as $\mathrm{P}$-glycoprotein (P-gp) and multidrugresistant protein 1 (MDR1). Polymorphisms in the $A B C B 1$ were shown to influence the cholesterol-lowering response to statins and the risk for statin-related muscular adverse events, such as myalgia in several studies (Gelissen, McLachlan, 2014; Gryn, Hegele, 2014; Patel et al., 2015; Alfonsi, Hegele, Gryn, 2016).

Three variants of the $A B C B 1(1236 \mathrm{C}>\mathrm{T}$, c. $2677 \mathrm{G}>\mathrm{T} / \mathrm{A}$ and c. $3435 \mathrm{C}>\mathrm{T}$ ) were studied in Brazilian hypercholesterolemic (HC) subjects treated with simvastatin and atorvastatin. Fiegenbaum et al. reported that carriers of c.1236T and c.2677non-G alleles had increased response to simvastatin long-term treatment. Moreover, three alleles of $A B C B 1$ (c.1236T, c.2677non-G and c.3435T) conferred lower risk for statin-induced ADRinduced (Fiegenbaum et al., 2005a). Our group described that $\mathrm{HC}$ subjects carrying $A B C B 1 \mathrm{~T} / \mathrm{T}$ haplotype have high basal serum concentrations of total and low-density lipoprotein (LDL) cholesterol but the $A B C B 1$ variants did not influence the response to short-term treatment with atorvastatin (Rodrigues et al., 2005). In a larger sample of HC subjects, we found that c.2677A allele is associated with greater LDL cholesterol reduction induced by atorvastatin (OR: 5.69, CI95\%: 1.28-25.24, $\mathrm{p}=0.022$ ). Interestingly, the c.2677T/A allele was also associated with reduction of $A B C B 1 \mathrm{mRNA}$ in PBMC (Rebecchi et al., 2009).

The variant $2012 \mathrm{G}>\mathrm{T}$ of the $A B C C 1$, which encodes the multidrug resistance-associated protein 1 (MRP1), was also investigated by our group. The $2012 \mathrm{~T}$ allele carriers had low basal HDL cholesterol levels, but this variant did not influence the response to atorvastatin (Rebecchi et al., 2009).

Uptake transporters, such as the organic anion transporter polypeptides (OATP), play also an important role in the efficacy and safety of statins. Polymorphisms in the $S L C O 1 B 1$, which encodes the organic anion- 


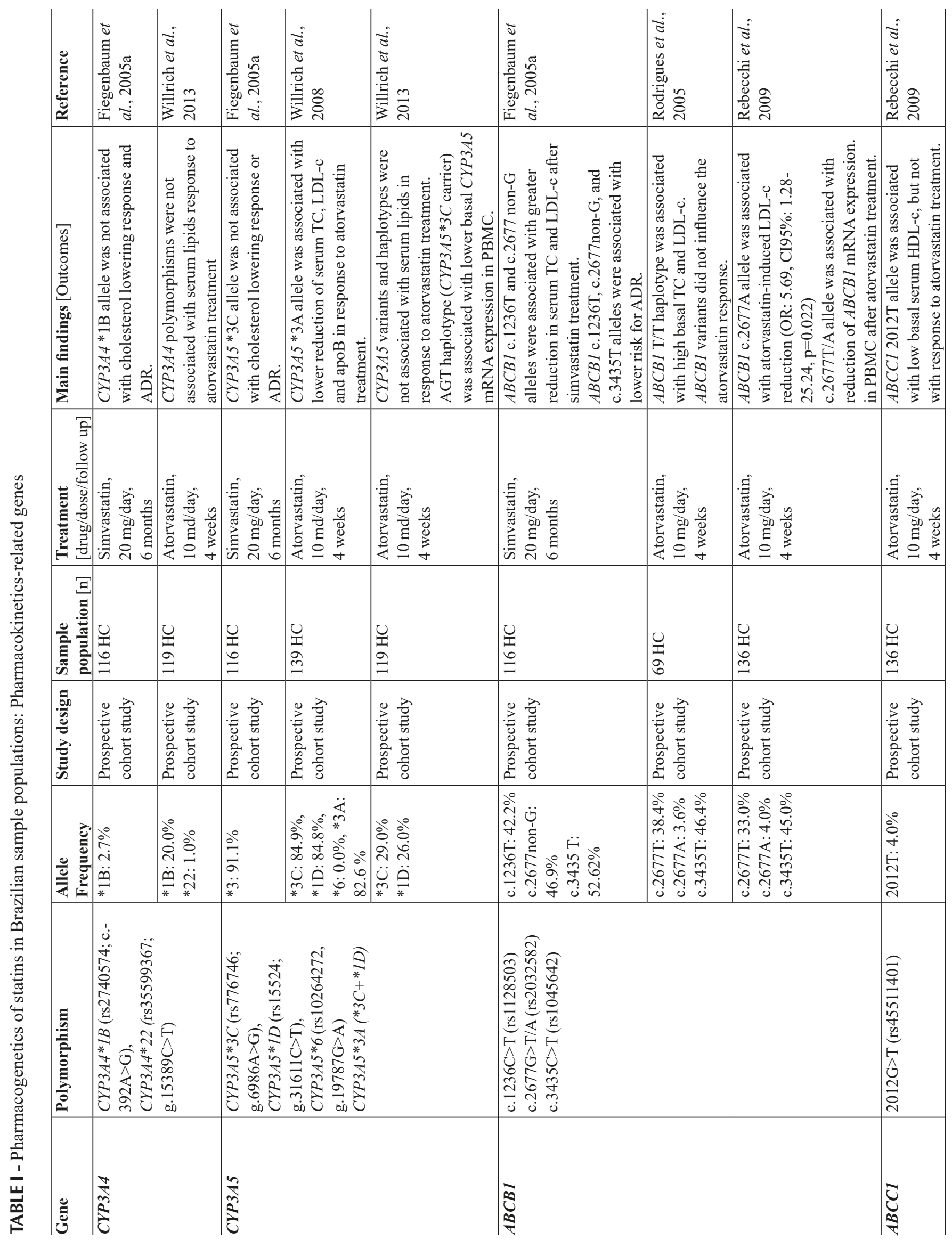




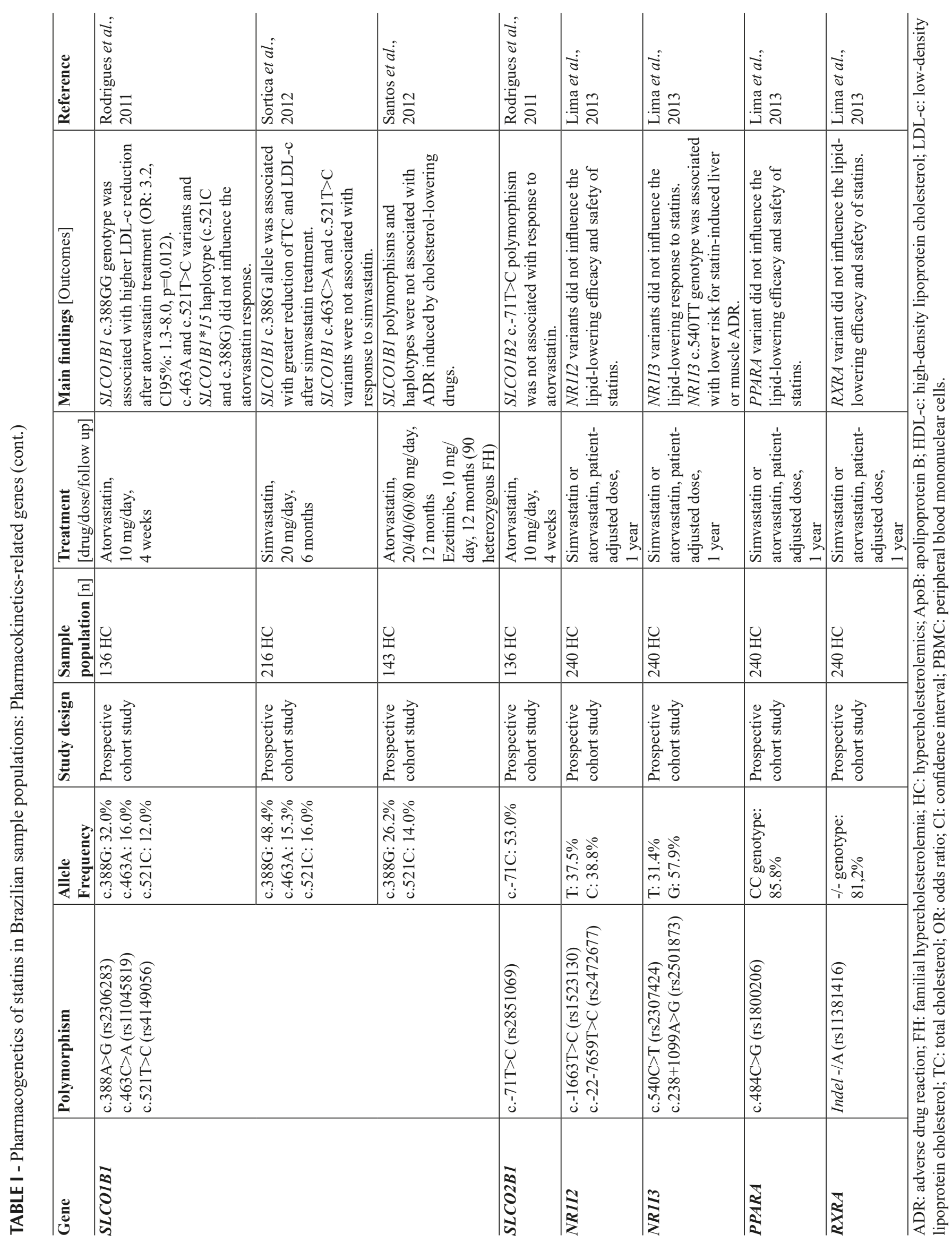


transporting polypeptide 1B1 (OATP1B1), are important predictors of the clinical response to statins, mainly the risk for statin-related muscular events (Gelissen, McLachlan, 2014; Gryn, Hegele, 2014; Patel et al., 2015; Alfonsi, Hegele, Gryn, 2016; Leusink et al., 2016). Based on the clinical evidence of simvastatin-induced myopathy, the Clinical Pharmacogenetics Implementation Consortium (CPIC) guidelines recommend dose adjustments in carriers of the SLCO1B1 rs4149056 C allele (c.521T >C) (Ramsey et al., 2014).

The $S L C O 1 B 1$ c. $388 \mathrm{~A}>\mathrm{G}, \mathrm{c} .463 \mathrm{C}>\mathrm{A}$ and c. $521 \mathrm{~T}>\mathrm{C}$ variants were studied in Brazilian HC subjects. Our research group reported that $S L C O 1 B 1$ c.388GG genotype carriers are more likely to have greater LDL cholesterol response to atorvastatin (OR: 3.2, CI95\%: 1.3-8.0, $\mathrm{p}=0.012$ ) but the c. $463 \mathrm{C}>\mathrm{A}$ and c.521T $>\mathrm{C}$ variants did not influence the atorvastatin response (Rodrigues et al., 2011). Similar results were described by Sortica et al, with the SLCO1B1 c. $388 \mathrm{G}$ allele associated with greater reduction of total and LDL cholesterol after long term treatment with simvastatin (Sortica et al., 2012). SLCO1B1 c.388A $>$ G and c.521T $>$ C variants were also investigated in a sample of heterozygous Familial Hypercholesterolemic (FH) subjects treated with atorvastatin (20-80 mg/day) and ezetimibe (10mg/day) for 12 months. SLCO1B1 polymorphisms and haplotypes were not associated with ADR induced by cholesterol-lowering drugs (Santos et al., 2012).

The variant c. $-71 \mathrm{~T}>\mathrm{C}$ of the $S L C O 2 B 1$, which encodes the membrane transporter OATP2B1, was also studied by our group, but no association was found with the lipid response to atorvastatin (Rodrigues et al., 2011).

Pregnane $X$ receptor (PXR), constitutive androsterone receptor (CAR), peroxisome proliferatoractivated receptor alpha (PPAR-alpha) and other nuclear receptors regulate the expression of major drug metabolizing enzymes and transporters upon induction by xenobiotics and pharmacological drugs. Polymorphisms in genes encoding PXR (NR1I2), CAR (NR1I3), PPARalpha $(P P A R A)$ and retinoic $\mathrm{X}$ receptor alpha (RXR-alpha, $R X R A$ ) have been suggested to influence variability in CYP3A expression and activity and they may influence drug response (Klein, Zanger, 2013).

One study investigated the influence of polymorphisms within the NR1I2, NR1I3, PPARA and $R X R A$ on simvastatin or atorvastatin response in Brazilian $\mathrm{HC}$ patients treated during one year. NR1I2 (c. $-1663 \mathrm{~T}>\mathrm{C}$, c. $-22-7659 \mathrm{~T}>\mathrm{C}), N R 113$ (c.540C $>$ T, c. $238+1099 \mathrm{~A}>\mathrm{G})$, PPARA (c. $484 \mathrm{C}>\mathrm{G}$ ) and $R X R A$ (Indel -/A) did not influence lipid-lowering response to these statins. NR1I3 c.540TT genotype carriers had lower risk for statin- induced liver or muscle ADR, but the other variants were not associated with safety of statins (Lima et al., 2013).

\section{Pharmacodynamics-related genes}

Polymorphisms in the $H M G C R$, which encodes the target of statins, and other genes involved in the cholesterol homeostasis and lipid metabolism have been proposed as predictors of the statin response. Studies that investigated the influence of pharmacodynamics-related genes on response to statins in Brazilian populations are depicted in Table II.

Some variants of the $H M G C R$ were associated with the response to statins. $H M G C R$ haplotype $\mathrm{H} 2$ and $\mathrm{H} 7$ carriers experienced a $5 \%$ to $20 \%$ lower reduction of LDL cholesterol after treatment with simvastatin. $H M G C R$ variants rs17244841 (SNP12) and rs17238540 (SNP29) were associated with lower LDL cholesterol reduction in response to pravastatin and atorvastatin. The HMGCR rs1724481, rs10474433 and rs17671591 polymorphisms were also associated with response to various statins (Gelissen, McLachlan, 2014; Gryn, Hegele, 2014; Patel et al., 2014; Alfonsi, Hegene, Gryn, 2016).

One study investigated the HMGCR SNP29 in Brazilian HC patients taking long term treatment with simvastatin or atorvastatin $(10-80 \mathrm{mg} /$ day $)$, but no association was found with oxidative stress biomarkers, such as plasma malondialdehyde, oxidized LDL and total antioxidant activity, and plasma tocopherol (Botelho et al., 2012).

LDL receptor mediates the uptake of LDL particles in the cell surface by binding to the apolipoprotein B $(\mathrm{ApoB})$, the structural protein of the very low-density lipoprotein (VLDL) and LDL. Variants in the LDL receptor encoding gene, $L D L R$, were described to be associated with increased plasma lipids, reduced response to several statins and high risk for cardiovascular events (Gelissen, McLachlan, 2014; Gryn, Hegele, 2014; Leusink et al., 2016; Postmus et al., 2014; Alfonsi, Hegele, Gryn, 2016; Ruaño et al., 2016).

Our group investigated the influence of three variants of the LDLR (Val653Val/AvaII, Asn591Asn/HincII and g.42716A $>$ G/PvuII) in HC subjects. $L D L R$ AvaII $(\mathrm{A}+\mathrm{A}+$ ) and PvuII (P1P1) genotypes were associated with high basal total cholesterol, LDL cholesterol and apoB plasma concentrations and reduced response of these lipids to fluvastatin (Salazar et al., 2000). Further we reported that the $L D L R$ c. $* 52 \mathrm{G}>\mathrm{A}$ variant, located in the 3 'UTR, was associated with lower risk of hypercholesterolemia (OR: $0.58,95 \% \mathrm{CI}$ : $0.34-0.99, \mathrm{p}=0.043$ ) but not with response to atorvastatin (Zambrano et al., 2015). 


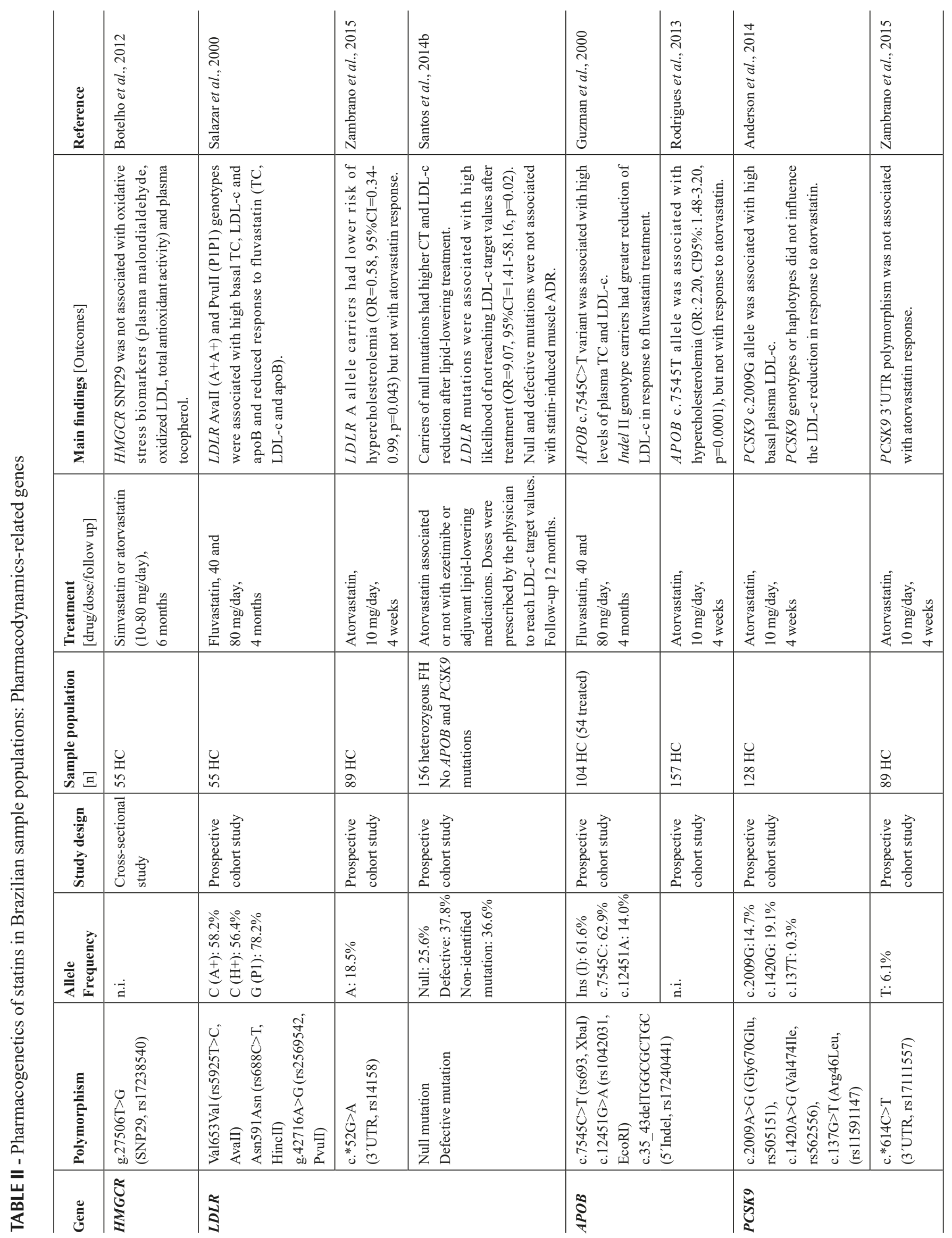




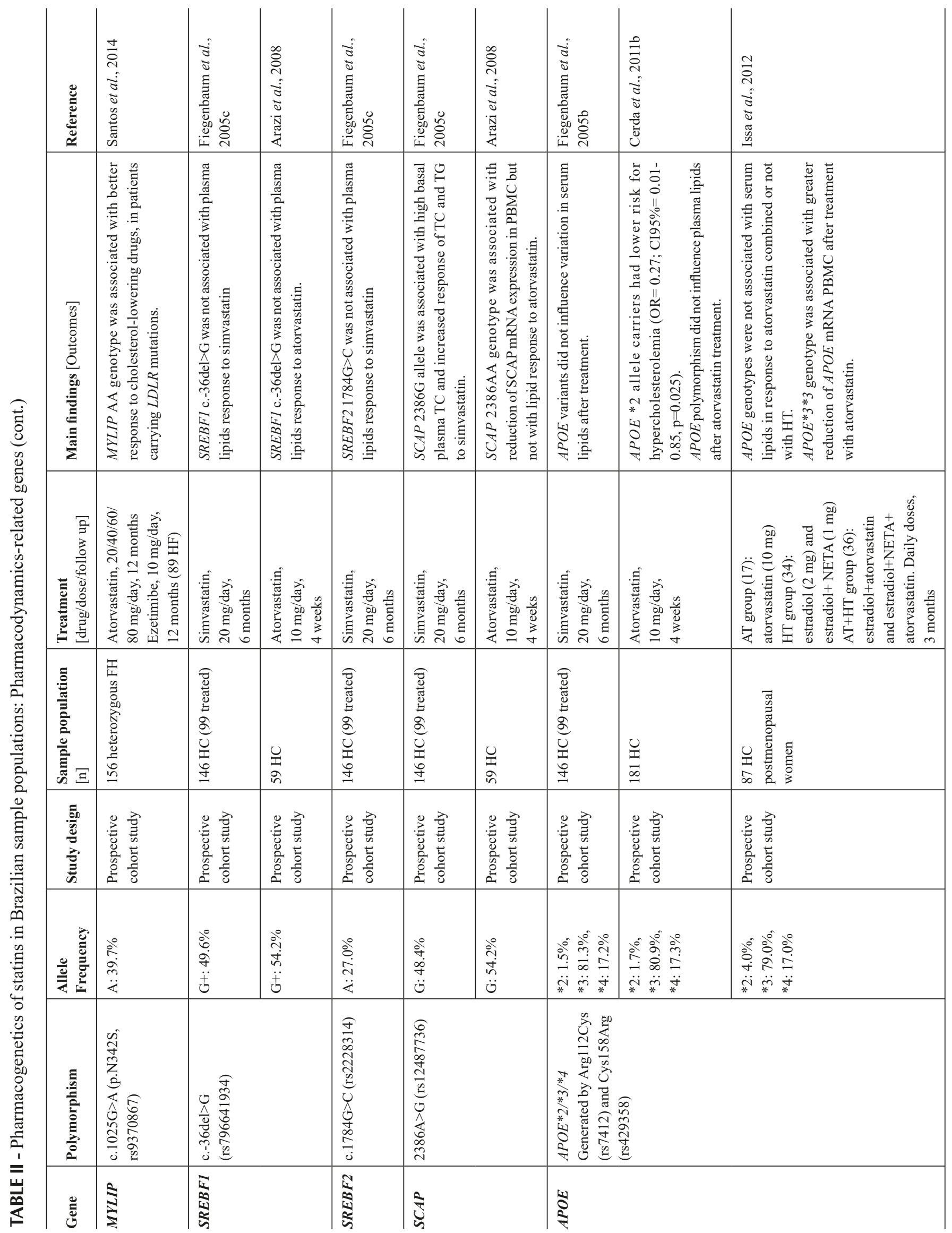




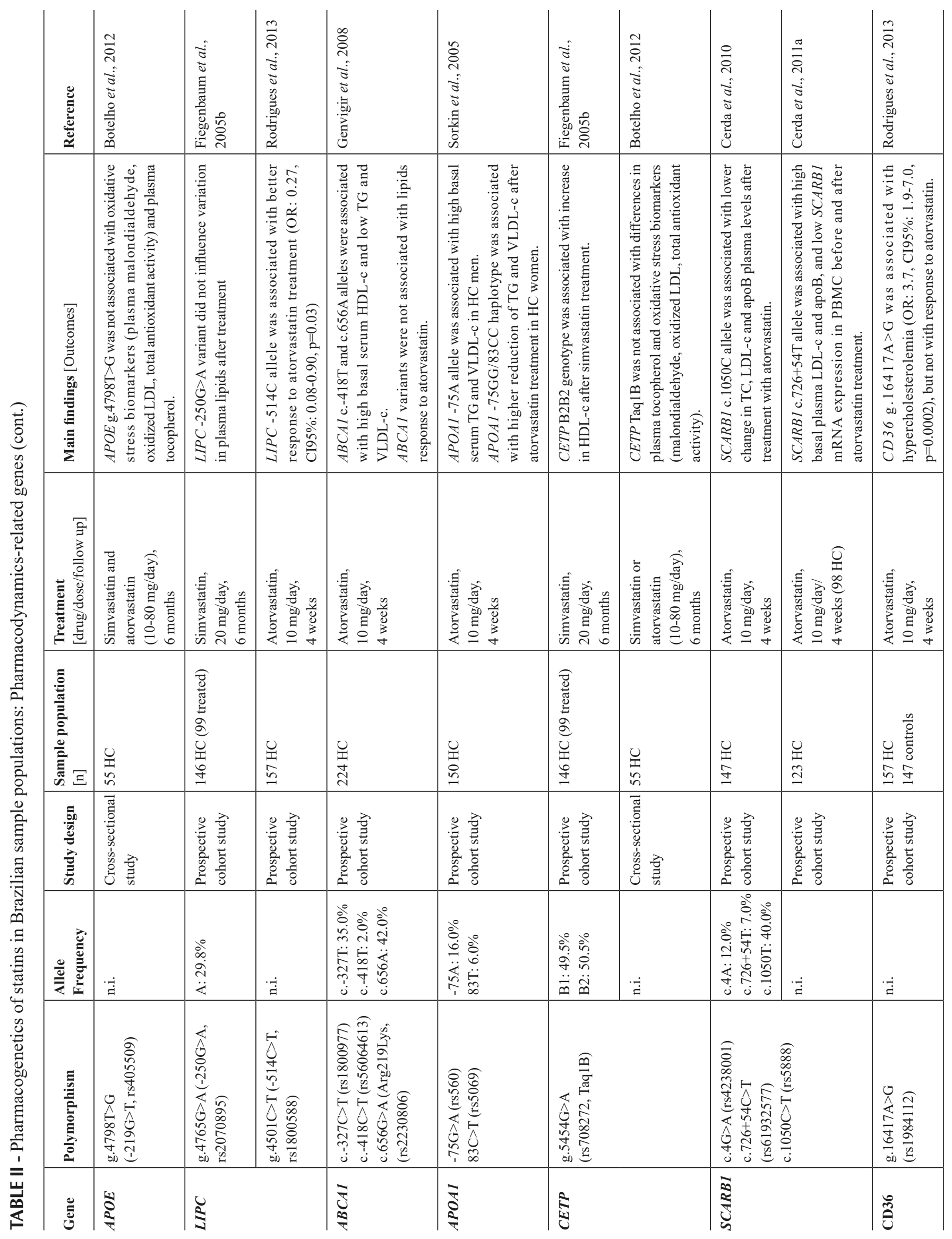




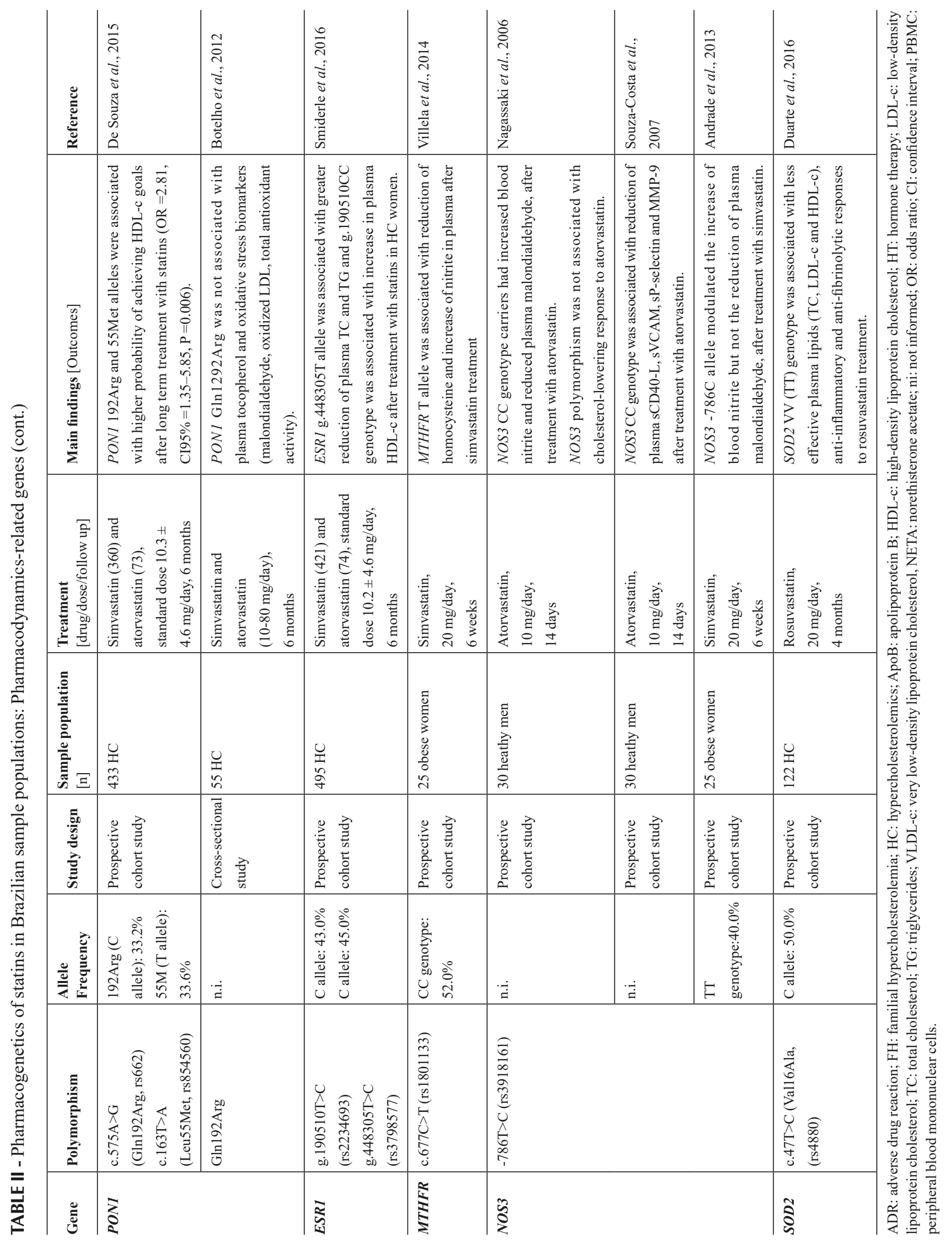


Santos et al investigated the influence of $L D L R$ mutations on response to long term (12 months) treatment with cholesterol-lowering drugs (atorvastatin associated or not with ezetimibe or adjuvant lipid-lowering drugs). Carriers of null mutations showed higher reduction of total and LDL cholesterol plasma levels after treatment. $L D L R$ mutations were associated with greater likelihood of not reaching LDL cholesterol target values after treatment (OR: 9.07, 95\% CI: 1.41-58.16, $\mathrm{p}=0.002$ ). In addition null and defective mutations were not associated with statininduced muscle ADR (Santos et al., 2014b).

$A P O B$ encodes $A p o B$, the ligand of LDL particles to the LDL receptor in the surface of the cells. Polymorphisms in $A P O B$ are associated with plasma ApoB and LDL cholesterol levels and risk of cardiovascular diseases (Benn, 2009).

The $A P O B$ c. $7545 \mathrm{C}>\mathrm{T}$, c. $12451 \mathrm{G}>\mathrm{A}$ and 5 'Indel polymorphisms have been studied in Brazilian samples. The c. $7545 \mathrm{C}>\mathrm{T}$ variant, also named XbaI, was associated with high levels of plasma total and LDL cholesterol (Guzman et al., 2000) and with hypercholesterolemia (OR: 2.2, 95\%CI: 1.48-3.2, $\mathrm{p}=0.0001$ ) (Rodrigues et $a l ., 2013)$. The insertion/deletion variant, located at the 5 'of the $A P O B$, was associated with greater reduction of plasma LDL cholesterol after long term treatment with fluvastatin (4 months), however c. $7545 \mathrm{C}>\mathrm{T}$ and c. $12451 \mathrm{G}>\mathrm{A}$ (EcoRI) did not influence the response to fluvastatin (Guzman et al., 2000) or short term treatment with atorvastatin (Rodrigues et al., 2013).

Proprotein convertase subtilisin/kexin type 9 (PCSK9) is an enzyme that degrades the LDL receptor, and contributes to the cholesterol intracellular homeostasis. Functional polymorphisms (gain in function) in PCSK 9 have been associated with a lower response to statins (Gelissen, McLachlan, 2014; Gryn, Hegele, 2014; Alfonsi, Hegele, Gryn, 2016). Whereas non-functional (loss of function) variants were related to increased statin response, which was the basis of the development of the PCSK9 inhibitors (Burke et al., 2017).

Four variants of the PCSK9 (c.2009A $>\mathrm{G}$, c. $1420 \mathrm{~A}>\mathrm{G}, \mathrm{c} .137 \mathrm{G}>\mathrm{T}$ and c. ${ }^{*} 614 \mathrm{~T}>\mathrm{C}$ ) were analyzed in Brazilian HC subjects, but no one was associated with response to short term treatment with atorvastatin (Anderson et al., 2014; Zambrano et al., 2015). Interestingly, carriers of the c. $2009 \mathrm{G}$ allele had higher basal plasma LDL cholesterol (Anderson et al., 2014).

The myosin regulatory light chain-interacting protein (MYLIP), also named E3-ubiquitin ligase, is a cytoskeletal effector protein that links actin to membranebound proteins at the cell surface. MYLIP causes the ubiquitination of the LDL receptor cytoplasmic domain, thereby promoting its degradation and rising plasma LDL cholesterol. Polymorphisms in MYLIP have been associated with variability in plasma cholesterol and response to statins (Gelissen, McLachlan, 2014).

Santos et al. investigated the influence of MYLIP c. $1025 \mathrm{G}>\mathrm{A}$ variant on plasma lipids in heterozygous FH patients. They showed that AA genotype was associated with better response to long term treatment with atorvastatin and ezetimibe, a cholesterol absorption inhibitor, in subjects carrying $L D L R$ mutations (Santos et al., 2014a).

\section{Cholesterol homeostasis-related genes}

Sterol regulatory element-binding factors (SREBFs) and SREBF cleavage-activating protein (SCAP) are important regulators of the cholesterol homeostasis, mostly by activating hepatic synthesis of fatty acids and cholesterol. SREBFs are activated by low level of intracellular cholesterol, in a sequence of steps including the SCAP-mediated transfer from endoplasmic reticulum to the Golgi. Activated SREPFs are transferred to nucleus to induce the transcription of the cholesterogenic genes, such as $H M G C R$ and $L D L R$ that results in normalization of the intracellular cholesterol level. Polymorphisms in the SREBF1, SREBF1 and SCAP encoding genes have been implicated in the variability of plasma lipids and in the response to lipid-lowering drug (Gryn, Hegele, 2014).

The influence of the SRBEF1, SREBF2 and $S C A P$ polymorphisms on lipid-lowering response to statins were evaluated in two studies with Brazilian HC subjects. $S R B E F 1$ c. $-36 \mathrm{del}>\mathrm{G}$ and $S R E B F 2$ c. $1784 \mathrm{G}>\mathrm{C}$ variants were not associated with plasma lipids response to simvastatin (Fiegenbaum et al., 2005c). We also did not find relationship between $S R B E F 1$ c.-36del $>$ G and the atorvastatin cholesterol-lowering response (Arazi et al., 2008). HC subjects carrying the $\mathrm{G}$ allele of the $S C A P 2386 \mathrm{~A}>\mathrm{G}$ polymorphism had high plasma total cholesterol and increased response of total cholesterol and triglycerides to simvastatin treatment for six months (Fiegenbaum et al., 2005c). Our research group reported that SCAP $2386 \mathrm{GG}$ genotype carriers had reduction of $S C A P$ mRNA expression in PBMC, but the polymorphism did not influence the lipid response to atorvastatin (Arazi et al., 2008).

\section{Lipid metabolism-related genes}

Apolipoprotein E (ApoE) has an important role in the liver uptake of the triglyceride-rich lipoproteins, such as VLDL and its remnant, via LDL and lipoprotein receptor-related protein (LRP) receptors. The gene encoding the ApoE $(A P O E)$ has three main alleles $(\varepsilon 2$, 
$\varepsilon 3$, and $\varepsilon 4$ ), which encodes ApoE isoforms with different affinities for cell surface receptors. Candidate genes and genome-wide association studies have suggested that $A P O E$ polymorphism is as a robust marker of statininduced cholesterol lowering response, but there is not a clear association with cardiovascular events (Gelissen, McLachlan, 2014; Gryn, Hegele, 2014; Patel et al., 2014; Postmus et al., 2014; Leusink et al., 2016; Ruaño et al., 2016).

Four studies evaluated of $A P O E$ polymorphism in Brazilian $\mathrm{HC}$ patients treated with statins. $A P O E$ alleles did not influence plasma lipids after long term treatment with simvastatin (Fiegenbaum et al., 2005b) and short term treatment with atorvastatin (Cerda et al., 2011b). We also reported no association between $A P O E$ genotypes and lipid-lowering response to atorvastatin combined or not with hormonal therapy for three months in postmenopausal HC women (Issa et al., 2012). As reported by previous studies, we found an association of $A P O E * 2$ allele with lower risk for hypercholesterolemia (OR: 0.27, CI95\%; 0.01-0.85, $\mathrm{p}=0.025)$ (Cerda et al., 2011b). Interestingly, $A P O E * 3 * 3$ genotype carriers had greater reduction of $A P O E$ mRNA levels in PBMC after atorvastatin treatment (Issa et al., 2012). Another study investigated the $A P O E$ g.4798T $>\mathrm{G}$ in subjects with statin-controlled dyslipidemia and did not find association with oxidative stress biomarkers and plasma tocopherol (Botelho et al., 2012).

Hepatic lipase, encoded by $L I P C$, has an important role in lipid metabolism by hydrolyzing triglycerides and phospholipids in plasma lipoproteins and by acting as a bridging factor for receptor-mediated lipoprotein uptake. Variants of LIPC have been associated with response to statins (Leusink et al., 2016).

Two studies investigated the influence of $L I P C$ polymorphisms in Brazilian HC patients treated with statins. Fiegenbaum et al reported lack of association between $L I P C-250 \mathrm{G}>\mathrm{A}$ and variability in plasma lipids after long term treatment with simvastatin (Fiegenbaum et al., 2005b). Whereas, our group described that $\mathrm{C}$ allele carriers of the $L I P C-514 \mathrm{C}>\mathrm{T}$ are more likely to have better response to atorvastatin (OR: 0.27, CI95\%: 0.08$0.90, \mathrm{p}=0.003$ ) (Rodrigues et al., 2013).

\section{Reverse cholesterol transport-related genes}

ABCA1 and ABCG1 are membrane transporters involved in the cholesterol efflux from cells to lipid poor apolipoprotein A-I (ApoA-I) in nascent discoidal HDL. In this way $\mathrm{ABCA} 1$ and $\mathrm{ABCG} 1$ transporters and ApoA-I as well play important roles in the biogenesis of HDL and the reverse transport of cholesterol from the cells to the liver. Polymorphisms in the gene cluster encoding apolipoproteins $A 1-C 3-A 4-A 5-B U D 13$ were reported to affect triglycerides and LDL cholesterol responses to statins (Gryn, Hegele, 2014).

Our group investigated the influence of three $A B C A 1$ polymorphisms (c.-327C $>$ T, c. $-418 \mathrm{C}>\mathrm{T}$ and c. $656 \mathrm{G}>\mathrm{A}$ ) and two $A P O A 1$ variants $(-75 \mathrm{G}>\mathrm{A}$ and $83 \mathrm{C}>\mathrm{T})$ on short term atorvastatin treatment. Carriers of $A B C A 1$ c. $-418 \mathrm{~T}$ and c.656A alleles had high basal serum HDL cholesterol and low triglycerides and VLDL cholesterol, but $A B C A 1$ variants were not associated of with response to atorvastatin (Genvigir et al., 2008). APOA1 -75A allele was associated with high basal serum triglycerides and VLDL cholesterol in $\mathrm{HC}$ men, and APOA $1-75 \mathrm{GG} / 83 \mathrm{CC}$ haplotype was associated with higher reduction of triglycerides and VLDL cholesterol after atorvastatin treatment in HC women (Sorkin et al., 2005).

Cholesteryl ester transfer protein (CETP) mediates the exchange of cholesteryl ester for triglycerides between HDL and the apoB-containing lipoproteins VLDL and LDL. Polymorphisms in CETP have been associated with variability in HDL cholesterol levels and cardiovascular events in patients treated with statins (Patel et al., 2014; Alfonsi, Hegele, Gryn, 2016; Leusink et al., 2016; Ruaño et al., 2016).

The influence of the CETP Taq1B (g.5454G $>$ A) polymorphism in $\mathrm{HC}$ treated with statins was reported in two Brazilian studies. CETP B2B2 genotype was shown to increase the HDL cholesterol after long term of simvastatin treatment (Fiegenbaum et al., 2005b). Whereas CETP Taq1B variant was not associated with differences in plasma tocopherol and oxidative stress biomarkers, such as malondialdehyde, oxidized LDL and total antioxidant activity, in a study with HC subjects treated with simvastatin or atorvastatin (Botelho et al., 2012).

The scavenger receptor BI (SR-BI) has also an important role in the final step of the reverse cholesterol transport, by mediating the liver uptake of the HDLassociated cholesterol esters, which are excreted through the bile. Several polymorphisms in genes involved in the cholesterol lowering pathway were investigated for modification of the effectiveness of statins in reducing the risk for myocardial infarction. SCARB1 variants had the most significant interaction with statin effectiveness (Peters et al., 2011).

Three polymorphisms (c. $4 \mathrm{G}>\mathrm{A}, \mathrm{c} .726+54 \mathrm{C}>\mathrm{T}$, c. $1050 \mathrm{C}>\mathrm{T}$ ) in the $S C A R B 1$, which encodes the SR$\mathrm{BI}$, were investigated by our group, in $\mathrm{HC}$ subjects treated with atorvastatin during 4 weeks. Carriers of $S C A R B 1$ c. 1050 C allele had less reduction of total cholesterol, LDL cholesterol and apoB plasma levels in response to atorvastatin (Cerda et al., 2010). SCARB1 
c. $726+54 \mathrm{~T}$ allele was associated with high basal plasma LDL cholesterol and apoB, and low SCARB1 mRNA expression in $\mathrm{PBMC}$ before and after atorvastatin treatment (Cerda et al., 2011a). SCARB1 variants were not associated with plasma lipids or $S C A R B 1 \mathrm{mRNA}$ expression in $\mathrm{PBMC}$ of $\mathrm{HC}$ subjects after treatment with ezetimibe $(10 \mathrm{mg} /$ day/4weeks $)$ and simvastatin $(10 \mathrm{mg} /$ day/8weeks) monotherapies and combined therapy (ezetimibe+simvastatin: $10 \mathrm{mg} /$ day/4weeks) (Cerda et al., 2011a).

Cluster determinant 36 (CD36), also named fatty acid translocase (FAT), is a membrane glycoprotein with various cellular functions, including oxidized LDL receptor (scavenger receptor type B), mechanisms of angiogenesis and gustatory perception of fatty acids. Using a candidate gene approach, we investigated the effects of polymorphisms in $C D 36$ and other genes related to lipid metabolism and atherosclerosis in a sample of Brazilian population. CD36 g. $16417 \mathrm{~A}>\mathrm{G}$ was associated with hypercholesterolemia (OR: 3.7, CI95\%: 1.9-7.0, $\mathrm{p}=0.0002)$, but not with response to short term treatment with atorvastatin (Rodrigues et al., 2013).

Paraoxonase 1 (PON1) is an enzyme with important roles in the detoxification of the oxidized LDL and prevention of the HDL lipid peroxidation. PON1 has been suggested to be a cardioprotective agent in atherosclerosis and related vascular diseases (Cerda, Hirata, Hirata, 2012). The polymorphisms c.575A $>\mathrm{G}$ (Gln192Arg) and c. $163 \mathrm{~T}>\mathrm{A}$ (Leu55Met) in the PON1 were studied in a sample of Brazilian HC subjects. Carriers of PON1 192Arg and 55Met alleles are more likely of achieving HDL cholesterol goals after long term treatment with simvastatin and atorvastatin (OR: 2.81, CI95\%:1.35-5.85, $\mathrm{P}=0.006)$ (De Souza et al., 2015). On the other hand PON1 Gln192Arg was not associated with differences in plasma tocopherol and oxidative stress biomarkers, in $\mathrm{HC}$ subjects treated with simvastatin or atorvastatin for six months (Botelho et al., 2012).

Estrogen receptor alpha, encoded by ESR 1, is a ligand-activated transcription factor involved in the signaling of the estrogen physiological effects in the female body, including the regulation of genes involved in the metabolism of HDL and other lipoproteins. Two variants in the ESR1 (g.190510T $>$ C and g.448305T $>$ C) were studied in a large sample of HC Brazilian subjects. g.448305T $>C$ was associated with greater reduction of plasma total cholesterol and LDL cholesterol after treatment with simvastatin and atorvastatin for six months, in HC women. Moreover, carriers of g.190510CC genotype showed increased HDL cholesterol in response to statins (Smiderle et al., 2016).

\section{Endothelial function-related genes}

Methylenetetrahydrofolate reductase (MTHFR) is involved in the methyl cycle generating 5-methylhydrofolate used for conversion of homocysteine to methionine. Endothelial dysfunction can be caused by hyperhomocysteinemia, which has been considered an independent risk factor for cardiovascular diseases. Polymorphisms in MTHFR and other genes were suggested to be predictors for slow atorvastatin metabolism (LeónCachón et al., 2016). A Brazilian study reported the association of MTHFR c.677C $>$ T polymorphism with homocysteine reduction and nitrite in plasma after simvastatin treatment, in obese women (Villela et al., 2014).

The endothelial nitric oxide synthase (eNOS) produces the vasodilator nitric oxide (NO), which regulates the vascular system by inhibition of platelet aggregation, leukocyte adhesion and smooth muscle proliferation. Variants in the eNOS encoding gene (NOS3) have been associated with myotoxicity of statins (Gryn, Hegele, 2014; Ruaño et al., 2016).

Three studies investigated the NOS $3-786 \mathrm{~T}>\mathrm{C}$ polymorphism was studied in Brazilian subjects. This variant was not associated with short term treatment with short term treatment with atorvastatin in health men, but blood nitrite was increased and plasma malondialdehyde was reduced in carriers of the NOS3 -786CC genotype (Nagasaki et al., 2006). The CC genotype was also associated with reduction of plasma SCD40-L, sVCAM, sP-selectin and MMP-9 in response to atorvastatin, in health men (Souza-Costa et al., 2007). NOS3 -786C allele was also associated with the increase in blood nitrite but not with the reduction of plasma malondialdehyde in obese women treated with simvastatin (Andrade et al., 2013).

Manganese-dependent superoxide dismutase (SOD2) is an antioxidant enzyme that prevents the deleterious effects of the superoxide anion, a reactive oxygen specie that is involved in the pathophysiology of atherosclerosis and other vascular diseases. The influence of SOD2 Val16Ala (c.47T $>$ C) on plasma lipids was evaluated in Brazilian HC patients. The VV (TT) genotype carriers had less intense reduction of plasma total and LDL cholesterol, anti-inflammatory and antifibrinolytic markers in response to long term treatment with rosuvastatin (Duarte et al., 2016).

\section{PHARMACOGENETICS AND DIABETES}

The increasing prevalence of obesity worldwide in the last decades have become this disease one of the most important public health problems nowadays, positioning to 
obesity-related metabolic diseases and CVD as one of the main causes of death in developed as well as developing countries (Bastien et al., 2014).

In this way, T2D has been considered a major health problem, affecting more than 415 million people. Several classes of antidiabetic drugs are currently prescribed, including mainly biguadines, sulfonylureas, meglitidines and thiazolidinediones (Chamberlain et al., 2017). The treatment strategy is mostly based on efficacy of oral antidiabetic drugs assessed by the level of fasting or postprandial glycaemia and/or glycated hemoglobin (HbA1c). Pharmacogenetic studies have proposed several genes involved in the response to antidiabetic drugs (Singh, Usman, Banerjee, 2016).

Curiously, in Brazilian population the influence of genetic variants in genes participating in pharmacokinetics/ pharmacodynamics of oral antidiabetic drugs are almost inexistent. We identified only one study from our research group that evaluated the role of polymorphisms in the genes encoding the tumor necrosis factor alpha (TNF) and interleukin 6 (ILG) in 53 T2D patients treated with pioglitazone, an antidiabetic drug that enhances the expression of the peroxisome proliferator-activated receptor-gamma (PPAR $\gamma$ ), leading to improved sensitivity to insulin but that also can induce bone loss. TNF $-308 \mathrm{G}>\mathrm{A}$ (g.4682G $>$ A, rs 1800629$)$ and IL6 -174G $>$ C (c. $-237 \mathrm{C}>\mathrm{G}$, rs 1800795) polymorphisms were not associated with pioglitazone response regarding glycemic control, however the $T N F-308 \mathrm{~A}$ allele carriers had lower values of total alkaline phosphatase (tALP) in T2D patients after pioglitazone treatment (Himelfarb et al., 2011).

Regarding the treatment of obesity, in the last years Brazilian studies have mainly focused in the evaluation of the role of genetic variation on the response to surgical treatment of obesity (Nicoletti et al., 2017); however, the influence of genetic polymorphisms on pharmacological strategies for weight loss have not been evaluated until now.

Evaluating the pharmacogenetic implications of antidiabetic and antiobesity drugs in Brazilian populations is challenge due to the scarce information in the scientific literature. Further studies are necessary in order to elucidate the contribution of genetic background of our population to the pharmacological response regarding the treatment of the most prevalent diseases related to cardiovascular risk.

\section{PHARMACOGENETICS AND HYPERTENSION}

Hypertension is a very important public health issue, because it affects about one billion adult globally and is the most important risk factor to causa mortis in the contemporary society: coronary artery diseases, stroke, renal dysfunction and heart failure (Savoia et al., 2017).

A small subset of the hypertensive population is affected by monogenic disease; however the majority of cases of hypertension are multifactorial and polygenic. There is a complex trait of etiology involving an intricate network between homeostasis of extracellular body fluid, vascular tone regulated by renal system, cardiac contractility, neuroendocrine system and others factors such as age, weight, ethnicity, lifestyle and diet (Savoia et al., 2017).

Currently, the most commonly used antihypertensives are: (i) angiotensin I-converting enzyme (ACE) inhibitors, such as enalapril; (ii) angiotensin II-receptor blockers (ARBs), such as losartan; (iii) $\beta$-blockers, for example, atenolol; (iv) calcium-channel blockers, such as nifedipine; and (v) diuretics, such as spironolactone or hydrochlorothiazide. Even though these antihypertensive drugs are effective and well tolerated, only about half of patients with treated hypertension achieve appropriate BP control (Savoia et al., 2017). This variability is caused by genetic and non-genetic factors, which are known can cause primary and secondary hypertension (CooperDeHoff, Johnson, 2016).

The pharmacogenetic approaches in Brazilian population have involved primary (majority) hypertensive patients (HP), resistant hypertensive patients (RHP), gestational hypertensive (GHP) and preeclamptic patients (PP). The studies including GHP and PP were recently and very well reviewed by Luizon et al. (2017). The main results of the pharmacogenetic studies with HP and RHP are described in this review.

HP have been defined as systolic BP (SBP) $\geq 140$ $\mathrm{mmHg}$ and diastolic BP (DBP) $\geq 90 \mathrm{mmHg}$, with BP measurement obtained from the average of three BP readings on at least two office visits with the individuals in the seated position. RHP have been defined according to the Statement of American Heart Association as all subjects with BP that remains above goal in spite of the concurrent use of 3 antihypertensive agents of different classes (ideally among them, a diuretic) in optimal doses. Also the definition includes patients whose BP is controlled using four or more antihypertensive medications (Malachias et al., 2016). By the way, the use of multiple drugs is an inherent limitation of the pharmacogenetic studies with RHP. The mechanisms of resistance to antihypertensive treatment are not fully elucidated, but have been associated to excess sodium and fluid retention, increased activation of the renin-angiotensin-aldosterone system (RAAS), heightened activity of the sympathetic nervous system, 
endothelial dysfunction, arterial stiffness, left ventricular hypertrophy, microalbuminuria and deregulation of inflammatory adipokines (Hwang et al., 2017).

The pharmacogenetic studies of antihypertensive drugs in samples of the Brazilian population are listed in the Table III.

\section{Pharmacokinetics-related genes}

Two Brazilian studies investigated the influence of polymorphisms in genes encoding drug metabolizing and transporters on response to antihypertensive therapy, including hydralazine.

Hydralazine is a vasodilator metabolized by an acetylation reaction mediated by $N$-acetyltransferase 2 (NAT2), a drug metabolizing enzyme. Several alleles of the NAT2, which encodes NAT2 enzyme, are associated with slow acetylation phenotypes (191A, 341C, 590A, 857A). Spinasse et al investigated 15 different NAT2 polymorphisms, including two new variants $(30 \mathrm{~T}>\mathrm{A}$ and $824 \mathrm{~T}>\mathrm{C}$ ), in Brazilian RHP prescribed with a therapeutic scheme containing hydralazine. In a subset of 61 patients, significant BP reductions were observed in the carriers of slow acetylator alleles. Four of RHP patients had hydralazine-induced adverse effects, and three of them were slow NAT2 acelylators (Spinasse et al., 2014).

The influence of $A B C B 1$ polymorphisms on antihypertensive response was also investigated in Brazilian subjects. $A B C B 1$ c. $3435 \mathrm{C}>\mathrm{T}$ (rs1045642) was not associated with resistance to antihypertensive treatment. Interestingly, in RHP, c.3435CC genotype was associated with higher BP (Lacchini et al., 2014).

\section{Pharmacodynamics-related genes}

The components of the RAAS pathway, such as ACE, angiotensinogen, angiotensin II receptor type 1 (AT1 receptor) and aldosterone, play an important role in BP control. The polymorphisms in the genes encoding RAAS proteins and other pharmacodynamics-related genes can influence the response to antihypertensive drugs. Results from pharmacogenetic studies in Brazilian HP are shown in Table III.

$A C E$ has a 287 bp insertion/deletion (g.16457_16458insG, Indel, rs 1799752) polymorphism in intron 16 that is the most well-known variant. The $A C E$ del variant has been associated with increased plasma levels of ACE, which potentially increases the BP (Thorn et al., 2010). Previous studies have analyzed the influence of the variant on the pharmacological response with contradictory results (Thorn et al., 2010). In Brazilian older women, no association was found between the $A C E$ Indel and the amplitude of the reduction of $\mathrm{BP}$ in response to antihypertensive drugs (Moraes et al., 2008). Likewise, $A C E$ rs1799752 was not a genetic risk factor for resistant hypertension (Yugar-Toledo et al., 2011).

Polymorphisms in the $A G T$, which encodes the angiotensinogen, such as the Met268Thr (rs699), have not been associated with differences in $\mathrm{BP}$ reduction after treatment with ACE inhibitors or ARBs (Konoshita et al., 2011). Interestingly, in individuals from Brazil treated with combinations of antihypertensive drugs (which is the case in RHP), there was an association between $A G T$ Met268Thr polymorphism and increased risk for resistant hypertension. The $268 \mathrm{Thr}$ carriers presented an increased risk, especially if they were older than 50 years (YugarToledo et al., 2011).

Polymorphisms in the gene encoding AT1 receptor ( $A G T R 1$ ) have been shown to be associated with differences in response to antihypertensive drugs (Fontana, Luizon, Sandrim, 2015). The AGTR1 c.*86A>C (rs5186) variant, that is located in the 3'UTR and may affect gene transcription, was studied in a sample of Brazilian older women, but no association was found with BP reduction.

Bradykinin is a potent vasoactive peptide that induces vasodilation, releases of $\mathrm{NO}$ and promotes water and sodium excretion, which are mediated by bradykinin receptors (BDKRs). Variants in the gene encoding BDKR type $\mathrm{B} 2(B D K R B 2)$ were associated with the risk of hypertension (Luo, Kang, Xu, 2015). Two polymorphisms in $B D K R B 2$, c. $-192 \mathrm{C}>\mathrm{T}(-58 \mathrm{C}>\mathrm{T})$ and Indel exon 1 $(\mathrm{BE} 1+9 /-9)$, have been studied in Brazilian hypertensive patients. BDKRB2 -58TT genotype was associated with poor response to enalapril, an ACE inhibitor. Moreover, $-58 \mathrm{CC}$ genotype was associated with better response depending on presence of NOS3 -786TC genotype (Silva et al., 2013). On the other hand, no association was found between $B D K R B 2,-58 \mathrm{C}>\mathrm{T}$ and the response to enalapril in another sample of Brazilian HP subjects (Oliveira-Paula et al., 2017). The Indel BE1 9-bp repeat sequence was also not associated with the response to antihypertensive therapy in HP subjects (Silva et al., 2013; Oliveira-Paula et al., 2017).

Aldosterone synthase is a member of the cytochrome P450 family responsible for the final step of aldosterone synthesis in the adrenal cortex. The gene encoding aldosterone synthase, $C Y P 11 B 2$, is the hot spot for essential hypertension susceptibility genes (Chen et al., 2015). The results of association studies between the CYP11B2 c.-344C>T (rs1799998) polymorphism and essential hypertension, or aldosterone levels, are controversial. In Brazilian individuals, this SNP was not 


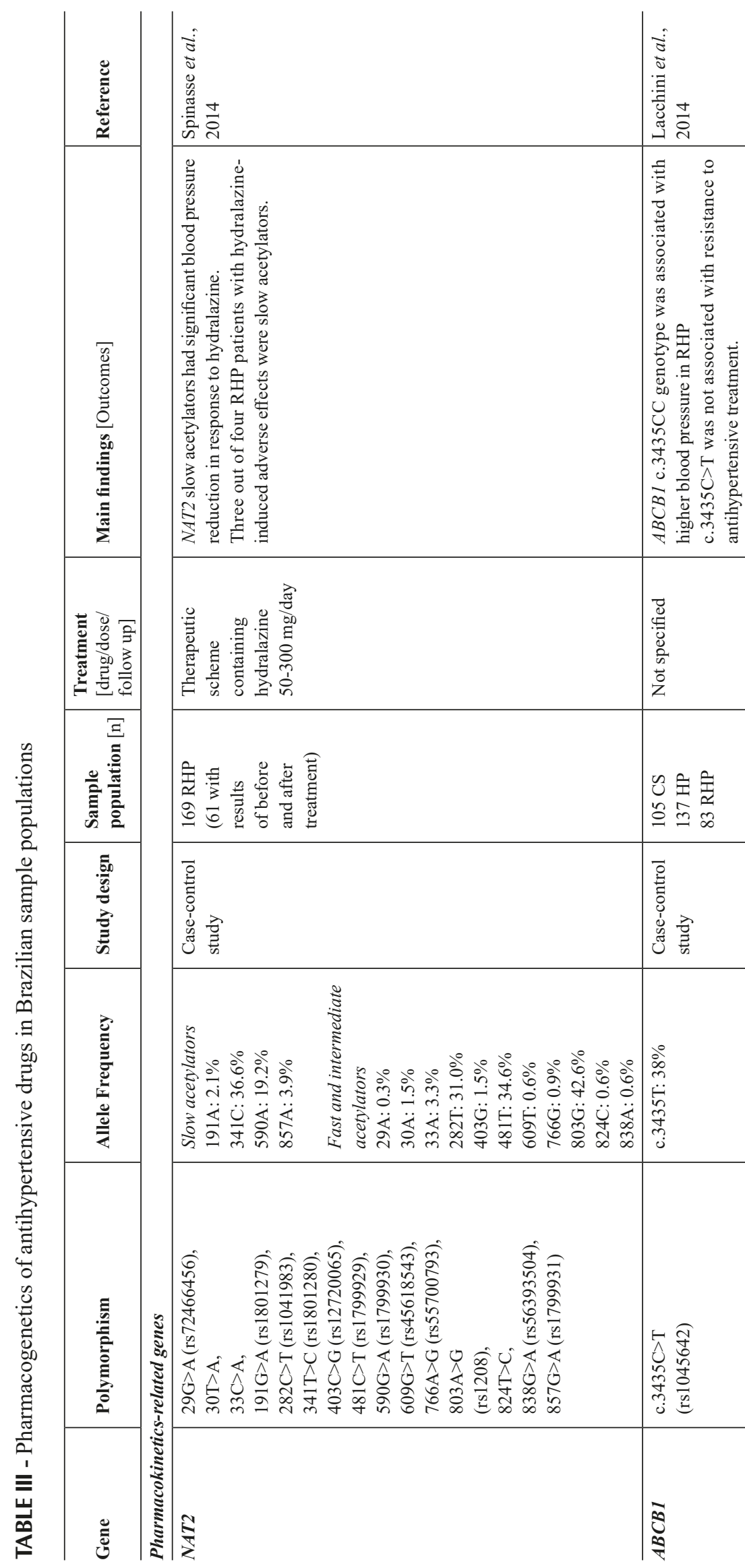

\begin{tabular}{|c|c|c|c|}
\hline 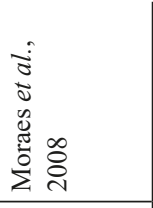 & 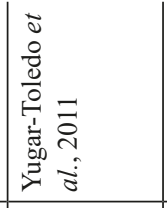 & 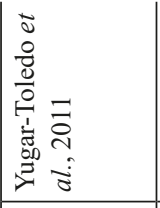 & 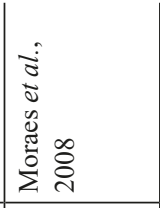 \\
\hline 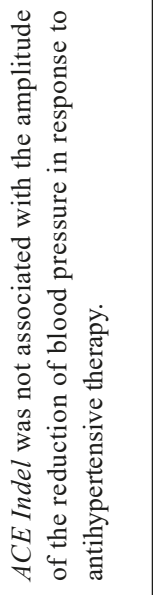 & 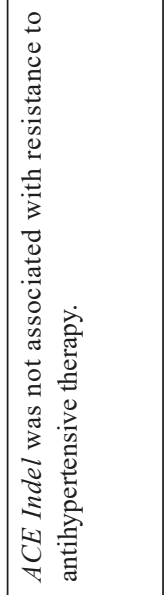 & 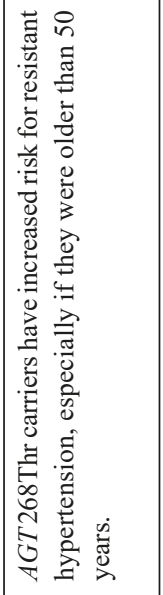 & 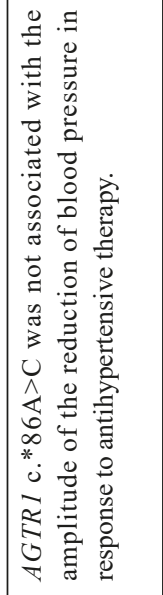 \\
\hline 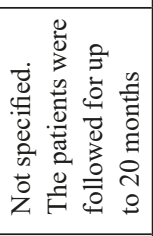 & 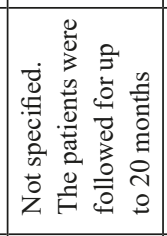 & 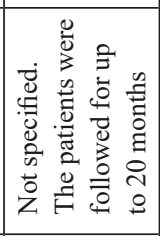 & 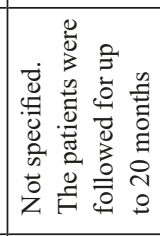 \\
\hline 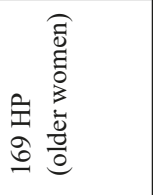 & $\begin{array}{l}0 \\
0 \\
0\end{array}$ & 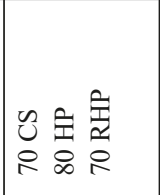 & 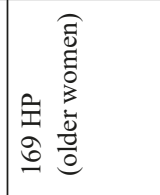 \\
\hline 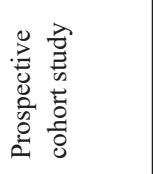 & 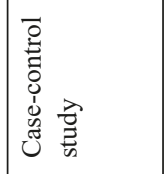 & 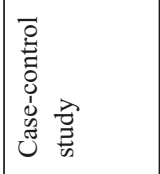 & 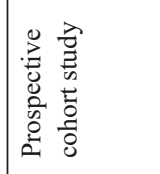 \\
\hline 站 & $\begin{array}{l}\stackrel{0}{0} \\
\text { ซे } \\
\ddot{g}\end{array}$ & 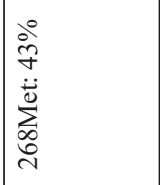 & 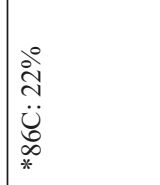 \\
\hline 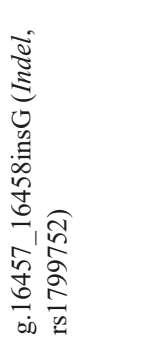 & & 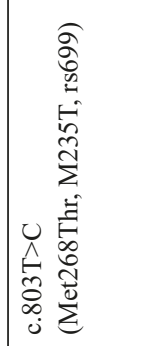 & 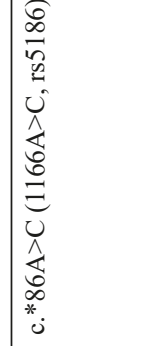 \\
\hline U & & $\underset{7}{\overparen{T}}$ & 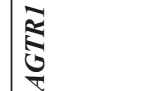 \\
\hline
\end{tabular}




\begin{tabular}{|c|c|c|c|c|c|c|c|c|c|c|}
\hline 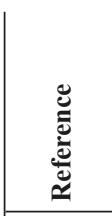 & 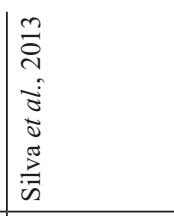 & 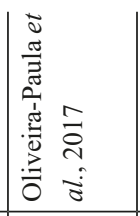 & 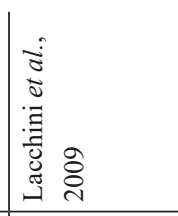 & 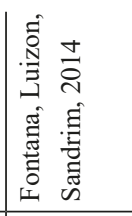 & 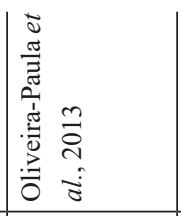 & 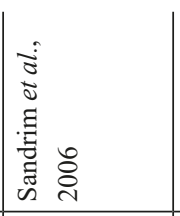 & 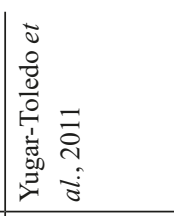 & 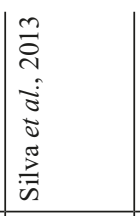 & 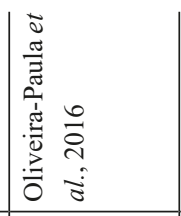 & 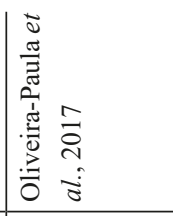 \\
\hline 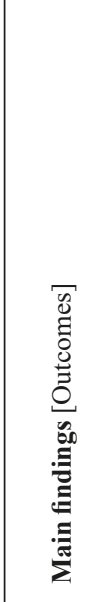 & 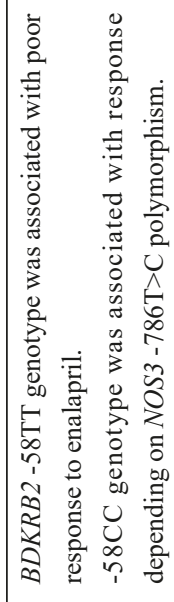 & 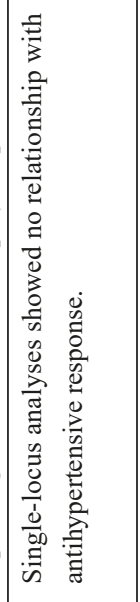 & 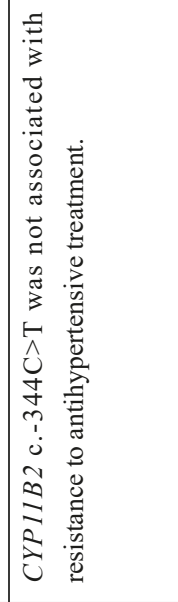 & 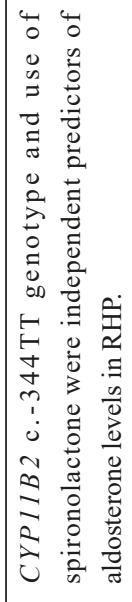 & 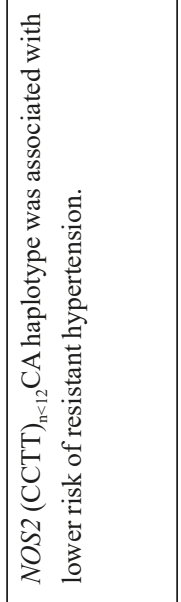 & 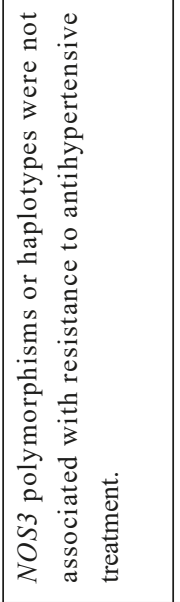 & 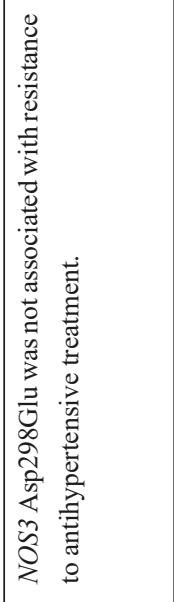 & 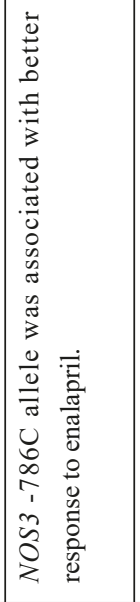 & 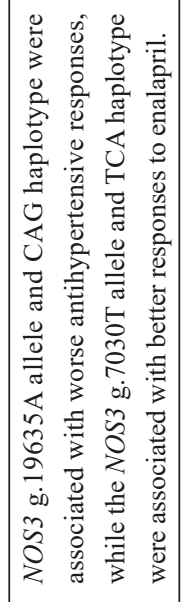 & 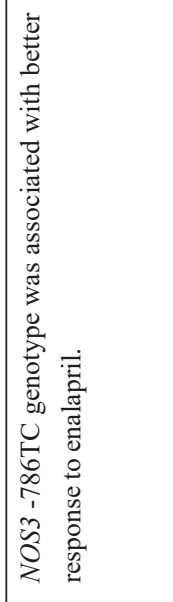 \\
\hline 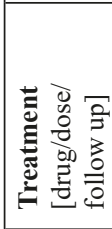 & 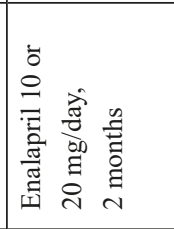 & 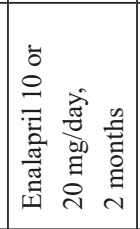 & 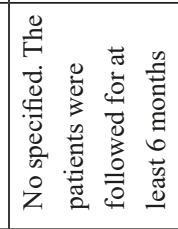 & 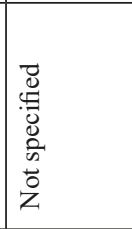 & 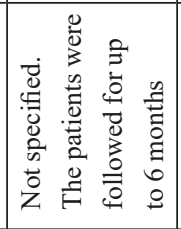 & 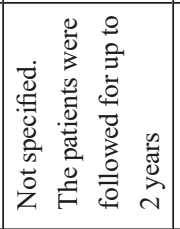 & 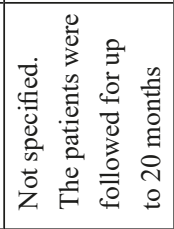 & 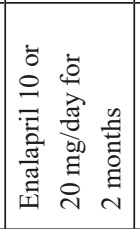 & 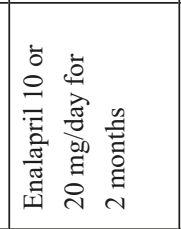 & 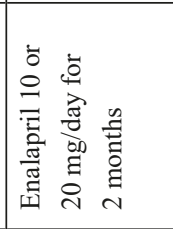 \\
\hline 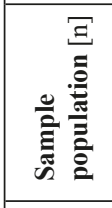 & $\begin{array}{l}\stackrel{1}{1} \\
8 \\
0\end{array}$ & 产 & 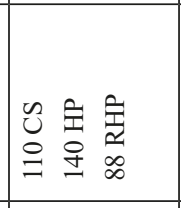 & 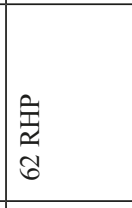 & 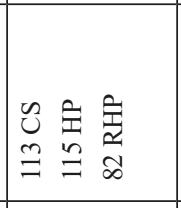 & 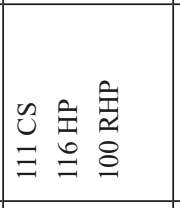 & 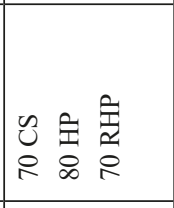 & $\begin{array}{l}\vdots \\
\vdots \\
\vdots\end{array}$ & $\begin{array}{l}\text { 主 } \\
\text { 을 }\end{array}$ & 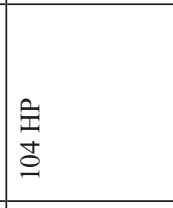 \\
\hline 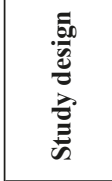 & 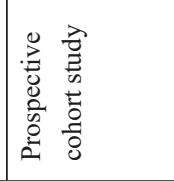 & 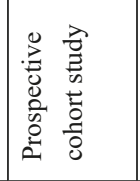 & 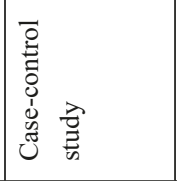 & 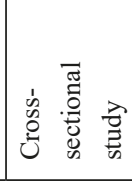 & 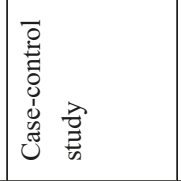 & 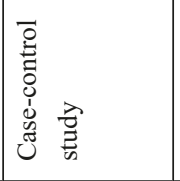 & 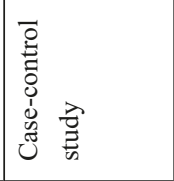 & 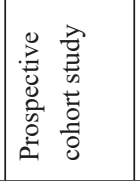 & 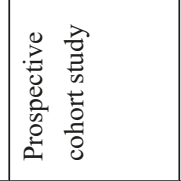 & 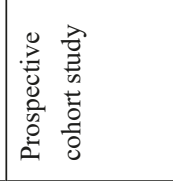 \\
\hline 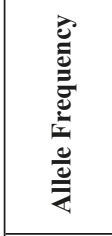 & 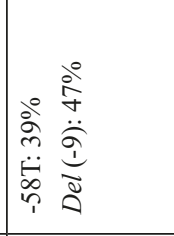 & 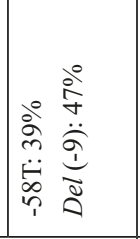 & 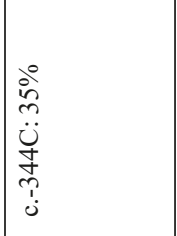 & 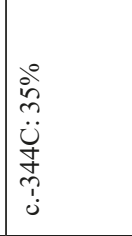 & 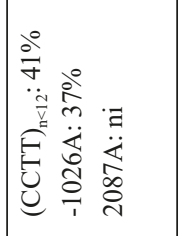 & 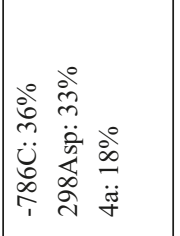 & 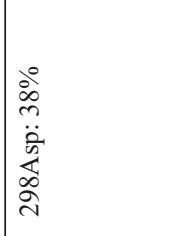 & 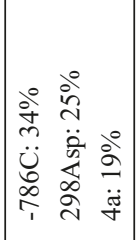 & 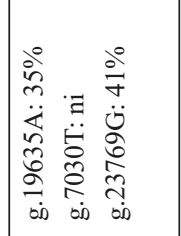 & 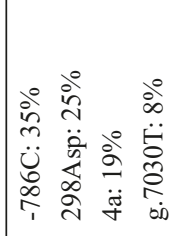 \\
\hline 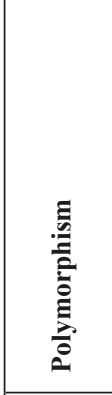 & 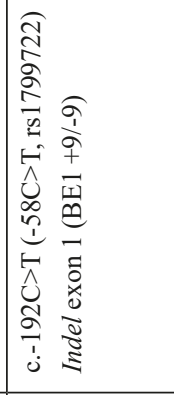 & & 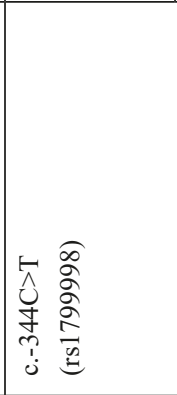 & & 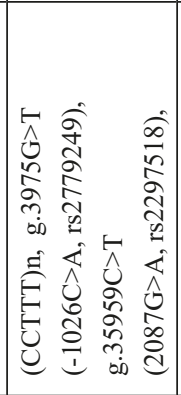 & 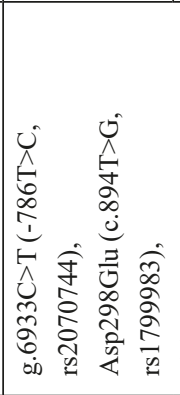 & & & 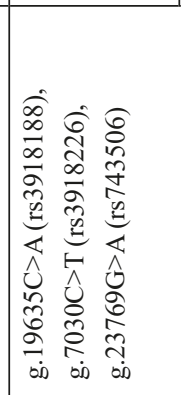 & \\
\hline Ü & 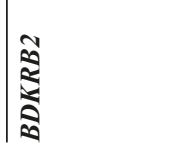 & & ڤี & & $\begin{array}{l}\tilde{\delta} \\
\text { है }\end{array}$ & $\mid \begin{array}{l}\hat{\tilde{y}} \\
\vdots \\
z\end{array}$ & & & & \\
\hline
\end{tabular}




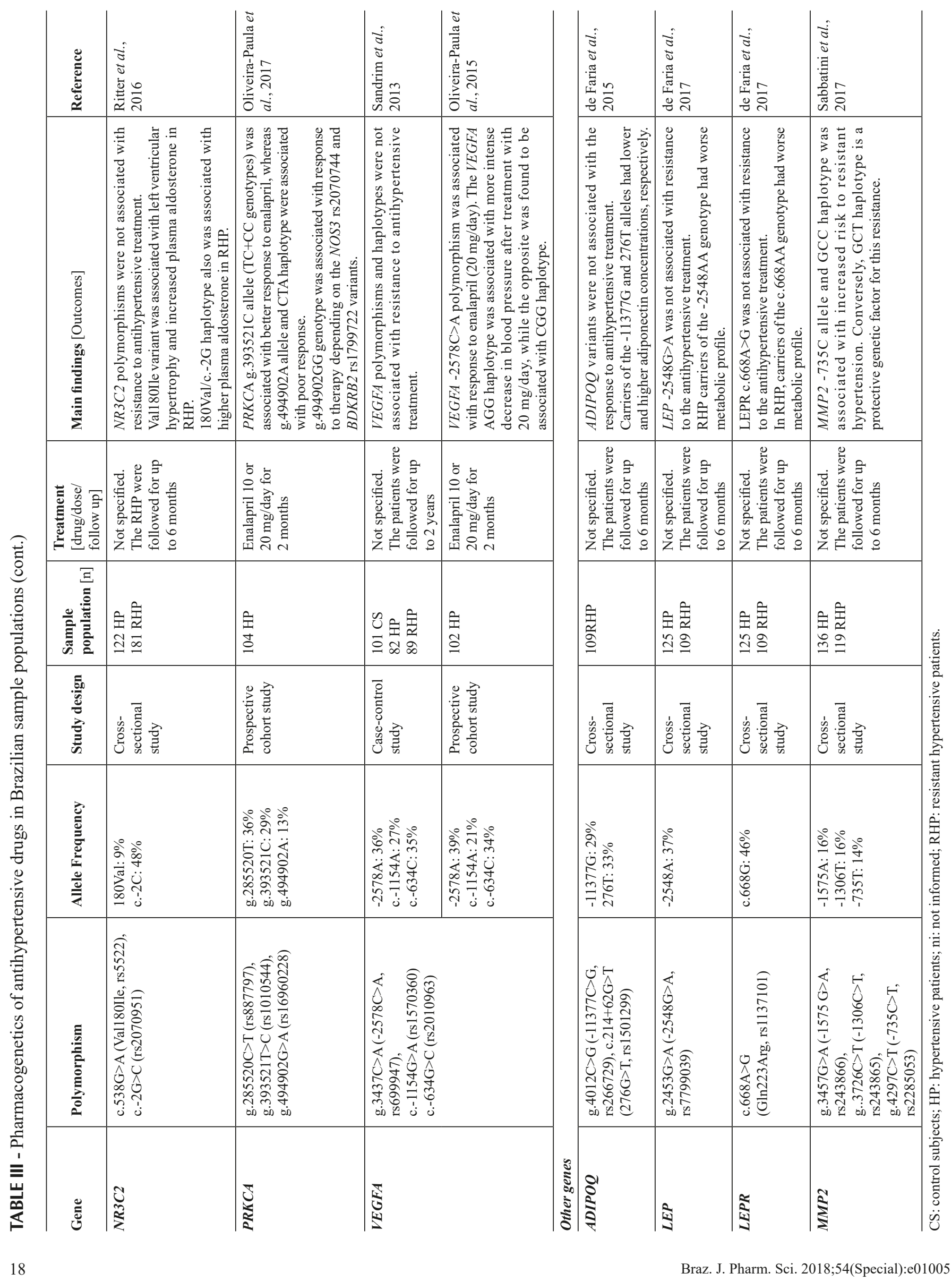


associated with resistant hypertension (Lacchini et al., 2009); nevertheless the c.-344TT genotype and use of spironolactone were independent predictors of aldosterone levels in RHP (Fontana et al., 2014).

The inducible oxide nitric synthase (iNOS, NOS2) is calcium-independent and generates more NO than the constitutive members, neuronal (nNOS, NOS1) and endothelial (eNOS, NOS3) isoforms. The regulation of NOS2 expression is stimulated by multiple factors including inflammatory cytokines and stress signals (Sorokin, 2016). Three variants in NOS2, the microsatellite (CCTTT)n, g.-1026C $>$ A (rs2779249) and g.2087G $>$ A (rs2297518), were investigated in Brazilian individuals. The results showed that (CCTT) ${ }_{\mathrm{n}<12} \mathrm{CA}$ haplotype was associated with lower risk of resistant hypertension (responsiveness to antihypertensive therapy) (OliveiraPaula et al., 2013).

NOS3, constitutively expressed in vascular endothelium, is the most important isoform for $\mathrm{NO}$ formation in the cardiovascular system (Sorokin, 2016). NOS3 variants have been the most studied in pharmacogenetic approaches with Brazilian hypertensive patients. The $-786 \mathrm{~T}>\mathrm{C}$ (rs2070744) polymorphism was not associated with resistance to antihypertensive therapy (Sandrim et al., 2006), but it seems to be related to a better therapeutic response to enalapril (Silva et al., 2013; Oliveira-Paula et al., 2017). Likewise, the NOS3 rs3918226T allele and TCA haplotype of the tagSNPs (rs3918188, rs3918226 and rs 743506) were associated with better response, whereas the rs3918188A allele and CAG haplotype were associated with worse antihypertensive response to enalapril 10 and/ or $20 \mathrm{mg}$ /day (Oliveira-Paula et al., 2016). The NOS3 Asp298Glu (rs1799983) and 4b/4a VNTR polymorphisms were not associated with responsiveness to therapy (Silva et al., 2013; Oliveira-Paula et al., 2017) or with resistance to treatment (Sandrim et al., 2006; Yugar-Toledo et al., 2011) in Brazilian individuals.

The mineralocorticoid receptor (MR) or nuclear receptor subfamily 3 , group c, member 2 (NR3C2) belongs to the nuclear receptor superfamily and functions as a ligand-dependent transcription factor that mediates the effects of aldosterone on a variety of target tissues. Variants in NR3C2, which encodes MR, affected BP response to enalapril treatment in Chinese hypertensive patients (Luo et al., 2014). In Brazilian individuals, the NR3C2 Val180Ile and c. $-2 \mathrm{G}>\mathrm{C}$ (rs2070951) polymorphisms were not associated with resistance to antihypertensive therapy. Interestingly, in RHP, increased levels of aldosterone and more prevalent left ventricular hypertrophy were associated with Val180Ile polymorphism. $180 \mathrm{Val} / \mathrm{c} .-2 \mathrm{G}$ haplotype also was associated with higher plasma aldosterone in RHP (Ritter et al., 2016).

Protein kinase $\mathrm{C}$ (PKC) signaling is involved in the vascular control mechanisms of BP. A genome wide association study (GWAS) revealed an intronic SNP, g.494902G $>$ A (rs16960228), in gene encoding of the isoform PKC alpha (PRKCA) as an important predictor of hydrochlorothiazide and atenolol response. The rs 16960228 A allele carriers had a greater hydrochlorothiazide BP response compared to GG carriers; however, an opposite direction of effect was found in participants treated with a $\beta$-blocker, atenolol (Cooper-DeHoff, Johnson, 2016). Three variants in PRKCA (rs887797, rs1010544 and rs16960228) were investigated in 104 Brazilian HP. PRKCA g.393521 (rs1010544) $\mathrm{C}$ allele was associated with better response to enalapril therapy, whereas the rs 16960228 A allele and CTA haplotype had the opposite effect. Moreover, the rs16960228 GG genotype combined with BDKRB2 -58CC (rs1799722) and NOS3 -786TC or TT (rs2070744) genotypes were associated with good or poor response to treatment, respectively (Oliveira-Paula et al., 2017).

Vascular endothelial growth factor (VEGF) has many biological roles, including migration and proliferation of endothelial cells and increase of vascular permeability. VEGF by stimulating NOS expression and $\mathrm{NO}$ activity also has a significant role in $\mathrm{BP}$ control (Mazidi et al., 2017). Because ACE inhibitors seem to up-regulate VEGF expression, Oliveira-Paula et al. (2015) investigated the influence of three VEGFA variants in Brazilian HP treated with enalapril. The authors found that after treatment with enalapril $20 \mathrm{mg}$ /day, the $-2578 \mathrm{C}>\mathrm{A}$ (rs699947) polymorphism predisposed to better antihypertensive response. Moreover, the haplotype AGG ( $-2578 \mathrm{C}>$ A, c. $-1154 \mathrm{G}>\mathrm{A}$ and c. $-634 \mathrm{G}>\mathrm{C}$ polymorphisms) was associated with more intense decrease in BP, while the opposite was found to be associated with the CGG haplotype. Conversely, these VEGFA polymorphisms were not associated with resistance to antihypertensive treatment in another sample of the Brazilian population (Sandrim et al., 2013).

\section{Other genes}

Polymorphisms in genes encoding adipokines, such as leptin $(L E P)$, leptin receptor $(L E P R)$ and adiponectin $(A D I P O Q)$, have been also studied in Brazilian sample population due to the relationship of alterations in these proteins with hypertension (Table III). ADIPOQ $(-11377 \mathrm{C}>\mathrm{G}$ and $276 \mathrm{G}>\mathrm{T}), \operatorname{LEP}(-2548 \mathrm{G}>\mathrm{A})$ and $L E P R$ (c. $668 \mathrm{~A}>\mathrm{G}$ ) were not associated with the response 
to antihypertensive therapy in RHP (de Faria et al., 2015; de Faria et al., 2017). Interestingly, carriers of ADIPOQ $-11377 \mathrm{G}$ and 276T alleles had lower and higher adiponectin concentrations, respectively (de Faria et al., 2015). Moreover, RHP carrying the LEP -2548AA or $L E P R$ c.668AA genotypes, compared to GG, presented a worse metabolic profile (de Faria et al., 2017).

Matrix metalloproteinases (MMPs) comprise a family of zinc and calcium-dependent proteases that degrade different components of the extracellular matrix, both in physiological and in pathophysiological conditions (Pulkoski-Gross, 2015). Previous review has showed the importance of MMP-2 in hypertension (Belo, Guimarães, Castro, 2015). The association of the three SNPs located in the promoter region of MMP2 $(-1575 \mathrm{G}>\mathrm{A},-1306 \mathrm{C}>\mathrm{T}$ and $-735 \mathrm{C}>\mathrm{T})$, with resistant hypertension was evaluated in Brazilian individuals (Table III). The -735C allele and GCC haplotype carriers showed increased risk to resistant hypertension, whereas the GCT haplotype had an opposite effect (Sabbatini et al., 2017).

\section{CONCLUSIONS AND FUTURE PERSPECTIVES}

Metabolic disorders represent an important group of pathologies and risk factors related to the development of CVD and the pharmacological and non-pharmacological management of these conditions are closely related to the high rates of morbidity and mortality by non-communicable diseases in our population. Genetic admixture of Brazilian populations is a challenge for genetic approaches to study complex disorders and multifactorial events, including pharmacogenetics, and frequently the data from welldefined ethnic groups are not applicable to Brazilian populations.

Pharmacogenetic studies of metabolic diseases in Brazilian population have explored a number of cardiovascular drugs for the treatment of dyslipidemia and hypertension; however, evaluating the role of genetic variability in response to antidiabetic drugs and pharmacological management of weight loss is still a challenge in this population. Considering that obesity and insulin resistance/T2D are the most prevalent diseases related to cardiovascular risk in developing countries, further pharmacogenetic studies are necessary in order to elucidate the contribution of genetic background of our population for effectiveness and safety of these drugs.

Pharmacogenetic studies of dyslipidemia have evaluated almost exclusively the response to statins, being necessary to expand the scope of pharmacogenetics to other lipid-lowering drugs. In the same line, it is also important to spread out the repertory of gene variants implicated in pharmacological response of cholesterollowering drugs to new mechanism of drug actions, mainly due to the broad applications of statin-induced pleiotropic effects.

Regarding pharmacogenetic studies of antihypertensive drugs, here the influence of genetic variants on HP and HRP in Brazilian populations was reviewed. Genetic causes of inadequate response to antihypertensive therapy are of great importance, mainly by the fact that a small proportion of these individuals achieve BP levels according to recommendations. Results from Brazilian studies demonstrated that response to antihypertensive drugs could be affected by the variability of diverse genes, including genes implicated in pharmacokinetics/ pharmacodynamics as also genes that not necessarily are directly involved in drug action. These studies have shown limitations in number and sample size, which make difficult to establish strong conclusions about their impact in our population.

In conclusion, although several pharmacogenetic studies evaluating drug response of metabolic diseases have been performed in Brazilian populations, a small sample size has been a constant in these studies, which limits the conclusions and clinical applications in our populations.

\section{ACKNOWLEDGMENTS}

FDVG is a recipient of fellowship from FAPESPBrazil. M.H. Hirata and R.D.C. Hirata are recipients of fellowships from CNPq-Brazil.

\section{REFERENCES}

Alfonsi JE, Hegele RA, Gryn SE. Pharmacogenetics of lipidlowering agents: precision or indecision medicine? Curr Atheroscler Rep. 2016;18(5):24.

Anderson JM, Cerda A, Hirata MH, Rodrigues AC, Dorea EL, Bernik MM, et al. Influence of PCSK9 polymorphisms on plasma lipids and response to atorvastatin treatment in Brazilian subjects. J Clin Lipidol. 2014;8(3):256-64.

Andrade VL, Sertório JT, Eleuterio NM, Tanus-Santos JE, Fernandes KS, Sandrim VC. Simvastatin treatment increases nitrite levels in obese women: modulation by $\mathrm{T}(-786) \mathrm{C}$ polymorphism of eNOS. Nitric Oxide. 2013;33:83-7. 
Arazi SS, Genvigir FD, Willrich MA, Hirata MH, Dorea EL, Bernik M, et al. Atorvastatin effects on SREBF1a and SCAP gene expression in mononuclear cells and its relation with lowering-lipids response. Clin Chim Acta. 2008;393(2):119-24.

Bastien M, Poirier P, Lemieux I, Després JP. Overview of epidemiology and contribution of obesity to cardiovascular disease. Prog Cardiovasc Dis. 2014;56(4):369-81.

Belo VA, Guimarães DA, Castro MM. matrix metalloproteinase 2 as a potential mediator of vascular smooth muscle cell migration and chronic vascular remodeling in hypertension. $\mathrm{J}$ Vasc Res. 2015;52(4):221-31.

Benn M. Apolipoprotein B levels, APOB alleles, and risk of ischemic cardiovascular disease in the general population, a review. Atherosclerosis. 2009;206(1):17-30.

Botelho PB, Fioratti CO, Rogero MM, Barroso LP, Bertolami MC, Castro IA. Association between diet and polymorphisms in individuals with statin-controlled dyslipidaemia grouped according to oxidative stress biomarkers. Braz J Pharm Sci. 2012;48(1):39-50.

Burke AC, Dron JS, Hegele RA, Huff MW. PCSK9: Regulation and target for drug development for dyslipidemia. Annu Rev Pharmacol Toxicol. 2017;57:223-244.

Cerda A, Genvigir FD, Arazi SS, Hirata MH, Dorea EL, Bernik MM, et al. Influence of SCARB1 polymorphisms on serum lipids of hypercholesterolemic individuals treated with atorvastatin. Clin Chim Acta. 2010;411(9-10):631-7.

Cerda A, Genvigir FD, Rodrigues AC, Willrich MA, Dorea EL, Bernik MM, et al. Influence of polymorphisms and cholesterol-lowering treatment on SCARB1 mRNA expression. J Atheroscler Thromb. 2011a;18(8):640-51.

Cerda A, Genvigir FD, Willrich MA, Arazi SS, Bernik MM, Dorea EL, et al. Apolipoprotein E mRNA expression in mononuclear cells from normolipidemic and hypercholesterolemic individuals treated with atorvastatin. Lipids Health Dis. 2011b;10:206.

Cerda A, Hirata MH, Hirata RD. Molecular mechanisms underlying statin effects on genes involved in the reverse cholesterol transport. Drug Metabol Drug Interact. 2012;27(2):101-11.

Cerda A, Hirata MH, Hirata RD. Pharmacogenetics of drug metabolizing enzymes in Brazilian populations. Drug Metabol Drug Interact. 2014;29:153-77.
Chamberlain JJ, Herman WH, Leal S, Rhinehart AS, Shubrook JH, Skolnik N, Kalyani RR. Pharmacologic Therapy for type 2 diabetes: Synopsis of the 2017 American Diabetes Association standards of medical care in diabetes. Ann Intern Med. 2017;166(8):572-8.

Chen JF, Jing J, Tan H, Song MB, Yu SY, Huang L. Lack of association of CYP11B2-344C/T polymorphism with essential hypertension: a meta-analysis. Int J Clin Exp Med. 2015;8(6):9162-7.

Cooper-DeHoff RM, Johnson JA. Hypertension pharmacogenomics: in search of personalized treatment approaches. Nat Rev Nephrol. 2016;12(2):110-22.

de Carvalho Vidigal F, Bressan J, Babio N, Salas-Salvadó J. Prevalence of metabolic syndrome in Brazilian adults: a systematic review. BMC Public Health. 2013;13:1198.

de Faria AP, Modolo R, Sabbatini AR, Barbaro NR, Corrêa NB, Brunelli V et al. Adiponectin $-11377 \mathrm{C} / \mathrm{G}$ and $+276 \mathrm{G} / \mathrm{T}$ polymorphisms affect adiponectin levels but do not modify responsiveness to therapy in resistant hypertension. Basic Clin Pharmacol Toxicol. 2015;117(1):65-72.

de Faria AP, Ritter AM, Sabbatini AR, Modolo R, Moreno H. Effects of leptin and leptin receptor SNPs on clinicaland metabolic-related traits in apparent treatment-resistant hypertension. Blood Press. 2017;26(2):74-80.

de Souza JA, Menin A, Lima LO, Smiderle L, Hutz MH, Van Der Sand CR, et al. PON1 polymorphisms are predictors of ability to attain HDL-C goals in statin-treated patients. Clin Biochem. 2015;48(16-17):1039-44.

Duarte T, da Cruz IB, Barbisan F, Capelleto D, Moresco RN, Duarte MM. The effects of rosuvastatin on lipid-lowering, inflammatory, antioxidant and fibrinolytics blood biomarkers are influenced by Val16Ala superoxide dismutase manganesedependent gene polymorphism. Pharmacogenomics J. 2016;16(6):501-506.

Faludi AA, Izar MCO, Saraiva JFK, Chacra APM, Bianco HT, Afiune A Neto, et al. Atualização da diretirz brazileira de dislipidemias e prevenção da aterosclerose - 2017. Arq Bras Cardiol. 2017;109(2 Supl 1):1-76. 
Fiegenbaum M, da Silveira FR, Van der Sand CR, Van der Sand LC, Ferreira ME, et al. The role of common variants of ABCB1, CYP3A4, and CYP3A5 genes in lipid-lowering efficacy and safety of simvastatin treatment. Clin Pharmacol Ther. 2005a;78(5):551-8.

Fiegenbaum M, da Silveira FR, Van der Sand CR, Van der Sand LC, Ferreira ME, Pires RC, et al. Pharmacogenetic study of apolipoprotein E, cholesteryl ester transfer protein and hepatic lipase genes and simvastatin therapy in Brazilian subjects. Clin Chim Acta. 2005b;362(1-2):182-8.

Fiegenbaum M, Silveira FR, Van der Sand CR, Van der Sand LC, Ferreira ME, Pires RC, et al. Determinants of variable response to simvastatin treatment: the role of common variants of SCAP, SREBF-1a and SREBF-2 genes. Pharmacogenomics J. 2005c;5(6):359-64.

Fontana V, de Faria AP, Barbaro NR, Sabbatini AR, Modolo R, Lacchini R, et al. Modulation of aldosterone levels by $-344 \mathrm{C} / \mathrm{T}$ CYP11B2 polymorphism and spironolactone use in resistant hypertension. J Am Soc Hypertens. 2014;8(3):146-51.

Fontana V, Luizon MR, Sandrim VC. An update on the pharmacogenetics of treating hypertension. J Hum Hypertens. 2015;29(5):283-91.

Gelissen IC, McLachlan AJ. The pharmacogenomics of statins. Pharmacol Res. 2014;88:99-106.

Genvigir FD, Soares SA, Hirata MH, Willrich MA, Arazi SS, Rebecchi IM et al. Effects of ABCA1 SNPs, including the C-105T novel variant, on serum lipids of Brazilian individuals. Clin Chim Acta. 2008;389(1-2):79-86.

Gouni-Berthold I, Berthold HK. Pharmacologic therapy for cardiovascular risk reduction in patients with the metabolic syndrome. Curr Pharm Des. 2014;20(31):5025-38.

Gryn SE, Hegele RA. Pharmacogenomics, lipid disorders, and treatment options. Clin Pharmacol Ther. 2014;96(1):36-47.

Guzmán EC, Hirata MH, Quintão EC, Hirata RD. Association of the apolipoprotein B gene polymorphisms with cholesterol levels and response to fluvastatin in Brazilian individuals with high risk for coronary heart disease. Clin Chem Lab Med. 2000;38(8):731-6.
Himelfarb ST, Silva FA, Arazi SS, Farjado CM, Garofalo A, Bertolami MC, et al. Tumor necrosis factor- $\alpha$ and interleukin-6 expression in leukocytes and their association with polymorphisms and bone markers in diabetic individuals treated with pioglitazone. Drug Metabol Drug Interact. 2011;26(1):3740.

Hwang AY, Dietrich E, Pepine CJ, Smith SM. Resistant Hypertension: Mechanisms and Treatment. Curr Hypertens Rep. 2017;19(7):56.

Issa MH, Cerda A, Genvigir FD, Cavalli SA, Bertolami MC, Faludi AA, et al. Atorvastatin and hormone therapy effects on APOE mRNA expression in hypercholesterolemic postmenopausal women. J Steroid Biochem Mol Biol. 2012;128(3-5):139-44.

Klein K, Zanger UM. Pharmacogenomics of Cytochrome P450 3A4: recent progress toward the "missing heritability" problem. Front Genet. 2013;4:12.

Konoshita T, Genomic Disease Outcome Consortium (G-DOC) Study Investigators. Do genetic variants of the ReninAngiotensin system predict blood pressure response to ReninAngiotensin system-blocking drugs?: a systematic review of pharmacogenomics in the Renin-Angiotensin system. Curr Hypertens Rep. 2011;13(5):356-61.

Lacchini R, Figueiredo VN, Demacq C, Coeli-Lacchini FB, Martins LC, Yugar-Toledo J, et al. MDR-1 C3435T polymorphism may affect blood pressure in resistant hypertensive patients independently of its effects on aldosterone release. J Renin Angiotensin Aldosterone Syst. 2014;15(2):170-6.

Lacchini R, Sabha M, Coeli FB, Favero FF, Yugar-Toledo J, Izidoro-Toledo $\mathrm{TC}$, et al. $\mathrm{T}$ allele of $-344 \mathrm{C} / \mathrm{T}$ polymorphism in aldosterone synthase gene is not associated with resistant hypertension. Hypertens Res. 2009;32(2):159-62.

León-Cachón RBR, Ascacio-Martínez JA, Gamino-Peña ME, Cerda-Flores RM, Meester I, Gallardo-Blanco HL, et al. A pharmacogenetic pilot study reveals MTHFR, DRD3, and MDR1 polymorphisms as biomarker candidates for slow atorvastatin metabolizers. BMC Cancer. 2016;16:74.

Leusink M, Onland-Moret NC, Bakker PIW, Boer A, Zee M. Seventeen years of statin pharmacogenetics: a systematic review. Pharmacogenomics. 2016;17(2):163-80. 
Lima LO, Bruxel EM, Hutz MH, Van der Sand CR, Van der Sand LC, Ferreira ME, et al. Influence of PPARA, RXRA, NR1I2 and NR1I3 gene polymorphisms on the lipid-lowering efficacy and safety of statin therapy. Arq Bras Endocrinol Metabol. 2013;57(7):513-9.

Luizon MR, Palei AC, Cavalli RC, Sandrim VC. Pharmacogenetics in the treatment of pre-eclampsia: current findings, challenges and perspectives. Pharmacogenomics. 2017;18(6):571-583.

Luo JQ, Wang LY, He FZ, Sun NL, Tang GF, Wen JG et al. Effect of NR3C2 genetic polymorphisms on the blood pressure response to enalapril treatment. Pharmacogenomics. 2014;15(2):201-8.

Luo K, Kang W, Xu G. The risk of bradykinin B2 receptor58T/C gene polymorphism on hypertension: a meta-analysis. Int J Clin Exp Med. 2015; 8(11):19917-27.

Malachias MVB, Rodrigues CIS, Muxfeldt E, Salles GF, Moreno $\mathrm{H}$ jr, Gus M. $7^{\text {th }}$ Brazilian Guileline of arterial hypertension: chapter 13 - Resistant arterial hypertension. Arq Braz Cardiol. 2016;107(3Suppl 3):75-8.

Mazidi M, Rezaie P, Kengne AP, Stathopoulou MG, AzimiNezhad M, Siest S. VEGF, the underlying factor for metabolic syndrome; fact or fiction? Diabetes Metab Syndr. 2017;11(Suppl 1):S61-S64.

Moraes CF, Souza ER, Souza VC, Medeiros EF, Gonçalves $\mathrm{TF}$, Toledo JO, et al. A common polymorphism in the renin angiotensin system is associated with differential outcome of antihypertensive pharmacotherapy prescribed to Brazilian older women. Clin Chim Acta. 2008;396(1-2):70-5.

Nagassaki S, Sertório JT, Metzger IF, Bem AF, Rocha JB, Tanus-Santos JE. eNOS gene T-786C polymorphism modulates atorvastatin-induced increase in blood nitrite. Free Radic Biol Med. 2006;41(7):1044-9.

Nicoletti CF, Cortes-Oliveira C, Pinhel MAS, Nonino CB. Bariatric surgery and precision nutrition. Nutrients. 2017;9(9):pii: E974.

Oliveira-Paula GH, Lacchini R, Coeli-Lacchini FB, Junior HM, Tanus-Santos JE. Inducible nitric oxide synthase haplotype associated with hypertension and responsiveness to antihypertensive drug therapy. Gene. 2013;515(2):391-5.
Oliveira-Paula GH, Lacchini R, Fontana V, Silva PS, Biagi C, Tanus-Santos JE. Polymorphisms in VEGFA gene affect the antihypertensive responses to enalapril. Eur J Clin Pharmacol. 2015;71(8):949-57.

Oliveira-Paula GH, Lacchini R, Luizon MR, Fontana V, Silva PS, Biagi C, et al. Endothelial nitric oxide synthase tagSNPs influence the effects of enalapril in essential hypertension. Nitric Oxide. 2016;55-56:62-9.

Oliveira-Paula GH, Luizon MR, Lacchini R, Fontana V, Silva PS, Biagi C, et al. Gene-gene interactions among PRKCA, NOS3 and BDKRB2 polymorphisms affect the antihypertensive effects of enalapril. Basic Clin Pharmacol Toxicol. 2017;120(3):284-91.

Patel J, Abd T, Blumenthal RS, Nasir K, Superko HR. Genetics and personalized medicine--a role in statin therapy? Curr Atheroscler Rep. 2014;16:384.

Patel J, Superko HR, Martin SS, Blumenthal RS, ChristopherStine L. Genetic and immunologic susceptibility to statin-related myopathy. Atherosclerosis. 2015;240:260-71.

Peters BJ, Pett H, Klungel OH, Stricker BH, Psaty BM, Glazer $\mathrm{NL}$, et al. Genetic variability within the cholesterol lowering pathway and the effectiveness of statins in reducing the risk of MI. Atherosclerosis. 2011;217(2):458-64.

Postmus I, Trompet S, Deshmukh HA, Barnes MR, Li X, Warren HR, Chasman DI, et al. Pharmacogenetic meta-analysis of genome-wide association studies of LDL cholesterol response to statins. Nat Commun. 2014;5:5068.

Pulkoski-Gross AE. Historical perspective of matrix metalloproteases. Front Biosci (Schol Ed). 2015:7:125-49.

Ramsey LB, Johnson SG, Caudle KE, Haidar CE, Voora D, Wilke RA, et al. The clinical pharmacogenetics implementation consortium guideline for SLCO1B1 and simvastatin-induced myopathy: 2014 update. Clin Pharmacol Ther. 2014;96(4):423-8.

Rebecchi IM, Rodrigues AC, Arazi SS, Genvigir FD, Willrich MA, Hirata MH, et al. ABCB1 and ABCC1 expression in peripheral mononuclear cells is influenced by gene polymorphisms and atorvastatin treatment. Biochem Pharmacol. 2009;77(1):66-75.

Ritter AM, Fontana V, Faria AP, Modolo R, Barbaro NR, Sabbatini AR, et al. Association of Mineralocorticoid Receptor Polymorphism I180V With Left Ventricular Hypertrophy in Resistant Hypertension. Am J Hypertens. 2016;29(2):245-50. 
Rodrigues AC, Perin PM, Purim SG, Silbiger VN, Genvigir FD, Willrich MA, et al. Pharmacogenetics of OATP transporters reveals that SLCO1B1 c.388A $>\mathrm{G}$ variant is determinant of increased atorvastatin response. Int J Mol Sci. 2011;12(9):581527.

Rodrigues AC, Rebecchi IM, Bertolami MC, Faludi AA, Hirata MH, Hirata RD. High basal serum total and LDL cholesterol levels are associated with MDR1 haplotypes in Brazilian hypercholesterolemic individuals of European. Braz J Med Biol Res. 2005;38(9):1389-97.

Rodrigues AC, Sobrino B, Genvigir FD, Willrich MA, Arazi $\mathrm{SS}$, Dorea EL, et al. Genetic variants in genes related to lipid metabolism and atherosclerosis, dyslipidemia and atorvastatin response. Clin Chim Acta. 2013;417:8-11.

Ruaño G, Seip R, Windemuth A, Wu AH, Thompson PD. Laboratory medicine in the clinical decision support for treatment of hypercholesterolemia: pharmacogenetics of statins. Clin Lab Med. 2016;36(3):473-91.

Sabbatini AR, Barbaro NR, de Faria AP, Ritter AMV, Modolo $\mathrm{R}$, Correa NB, et al. Matrix metalloproteinase-2 -735C/T polymorphism is associated with resistant hypertension in a specialized outpatient clinic in Brazil. Gene. 2017;620:23-29.

Salazar LA, Hirata MH, Quintão EC, Hirata RD. Lipidlowering response of the $\mathrm{HMG}-\mathrm{CoA}$ reductase inhibitor fluvastatin is influenced by polymorphisms in the low-density lipoprotein receptor gene in Brazilian patients with primary hypercholesterolemia. J Clin Lab Anal. 2000;14(3):125-31.

Sandrim VC, Luizon MR, Izidoro-Toledo TC, Coelho EB, Moreno H Jr, Tanus-Santos JE. Functional VEGF haplotypes affect the susceptibility to hypertension. J Hum Hypertens. 2013;27(1):31-7.

Sandrim VC, Yugar-Toledo JC, Desta Z, Flockhart DA, Moreno H Jr, Tanus-Santos JE. Endothelial nitric oxide synthase haplotypes are related to blood pressure elevation, but not to resistance to antihypertensive drug therapy. J Hypertens. 2006;24(12):2393-7.

Santos PC, Gagliardi AC, Miname MH, Chacra AP, Santos RD, Krieger JE, et al. SLCO1B1 haplotypes are not associated with atorvastatin-induced myalgia in Brazilian patients with familial hypercholesterolemia. Eur J Clin Pharmacol. 2012;68(3):273-9.
Santos PC, Morgan AC, Jannes CE, Krieger JE, Santos RD, Pereira AC. The MYLIP p.N342S polymorphism is associated with response to lipid-lowering therapy in Brazilian patients with familial hypercholesterolemia. Pharmacogenet Genomics. 2014a;24(11):548-55.

Santos PC, Morgan AC, Jannes CE, Turolla L, Krieger JE, Santos RD, et al. Presence and type of low density lipoprotein receptor (LDLR) mutation influences the lipid profile and response to lipid-lowering therapy in Brazilian patients with heterozygous familial hypercholesterolemia. Atherosclerosis. 2014b;233(1):206-10.

Savoia C, Volpe M, Grassi G, Borghi C, Agatibi Rosei F, Touyz RM. Personalized medicine - a modern approach for gthe diagnosis and management of hypertension. Clin Sci (Lond). 2017;131(22):2671-85.

Silva PS, Fontana V, Luizon MR, Lacchini R, Silva WA Jr, Biagi C, et al. eNOS and BDKRB2 genotypes affect the antihypertensive responses to enalapril. Eur J Clin Pharmacol. 2013;69(2):167-77.

Singh S, Usman K, Banerjee M. Pharmacogenetic studies update in type 2 diabetes mellitus. World J Diabetes. 2016;7(15):302315.

Smiderle L, Fiegenbaum M, Hutz MH, Van Der Sand CR, Van Der Sand LC, Ferreira ME, et al. ESR1 polymorphisms and statin therapy: a sex-specific approach. Pharmacogenomics J. 2016;16(6):507-513.

Sorkin SC, Forestiero FJ, Hirata MH, Guzmán EC, Cavalli $\mathrm{SA}$, Bertolami MC, et al. APOA1 polymorphisms are associated with variations in serum triglyceride concentrations in hypercholesterolemic individuals. Clin Chem Lab Med. 2005;43(12):1339-45.

Sorokin A. Nitric oxide synthase and cyclooxygenase pathways: a complex interplay in cellular signaling. Curr Med Chem. 2016; 23(24):2559-2578.

Sortica VA, Fiegenbaum M, Lima LO, Van der Sand CR, Van der Sand LC, Ferreira ME, et al. SLCO1B1 gene variability influences lipid-lowering efficacy on simvastatin therapy in Southern Brazilians. Clin Chem Lab Med. 2012;50(3):441-8.

Souza-Costa DC, Sandrim VC, Lopes LF, Gerlach RF, Rego EM, Tanus-Santos JE. Anti-inflammatory effects of atorvastatin: modulation by the T-786C polymorphism in the endothelial nitric oxide synthase gene. Atherosclerosis. 2007;193(2):438-44. 
Spinasse LB, Santos AR, Suffys PN, Muxfeldt ES, Salles GF. Different phenotypes of the NAT2 gene influences hydralazine antihypertensive response in patients with resistant hypertension. Pharmacogenomics. 2014;15(2):169-78.

Thorn CF, Klein TE, Altman RB. PharmGKB summary: very important pharmacogene information for angiotensin-converting enzyme. Pharmacogenet Genomics. 2010;20(2):143-6.

Villela MP, Andrade VL, Eccard B, Jordão AA, Sertório JT, Tanus-Santos JE, et al. Homocysteine and nitrite levels are modulated by MTHFR $677 \mathrm{C}>\mathrm{T}$ polymorphism in obese women treated with simvastatin. Clin Exp Pharmacol Physiol. 2014;41(10):744-7.

Willrich MA, Hirata MH, Genvigir FD, Arazi SS, Rebecchi IM, Rodrigues AC, et al. CYP3A53A allele is associated with reduced lowering-lipid response to atorvastatin in individuals with hypercholesterolemia. Clin Chim Acta. 2008;398(1-2):1520 .
Willrich MA, Rodrigues AC, Cerda A, Genvigir FD, Arazi SS, Dorea EL, et al. Effects of atorvastatin on CYP3A4 and CYP3A5 mRNA expression in mononuclear cells and CYP3A activity in hypercholeresterolemic patients. Clin Chim Acta. 2013;421:157-63.

Yoo HJ, Choi KM. Adipokines as a novel link between obesity and atherosclerosis. World J Diabetes. 2014;5(3):357-63.

Yugar-Toledo JC, Martin JF, Krieger JE, Pereira AC, Demacq $\mathrm{C}$, Coelho OR, et al. Gene variation in resistant hypertension: multilocus analysis of the angiotensin 1-converting enzyme, angiotensinogen, and endothelial nitric oxide synthase genes. DNA Cell Biol. 2011;30(8):555-64.

Zambrano T, Hirata MH, Cerda Á, Dorea EL, Pinto GA, Gusukuma MC et al. Impact of 3'UTR genetic variants in PCSK9 and LDLR genes on plasma lipid traits and response to atorvastatin in Brazilian subjects: a pilot study. Int J Clin Exp Med. 2015;8(4):5978-88. eCollection 2015. 